\title{
Exercise Testing in Firefighters \\ Work Capacity and Cardiovascular Risk Assessment in a Low-Risk Population
}

\section{Anna Carlén}

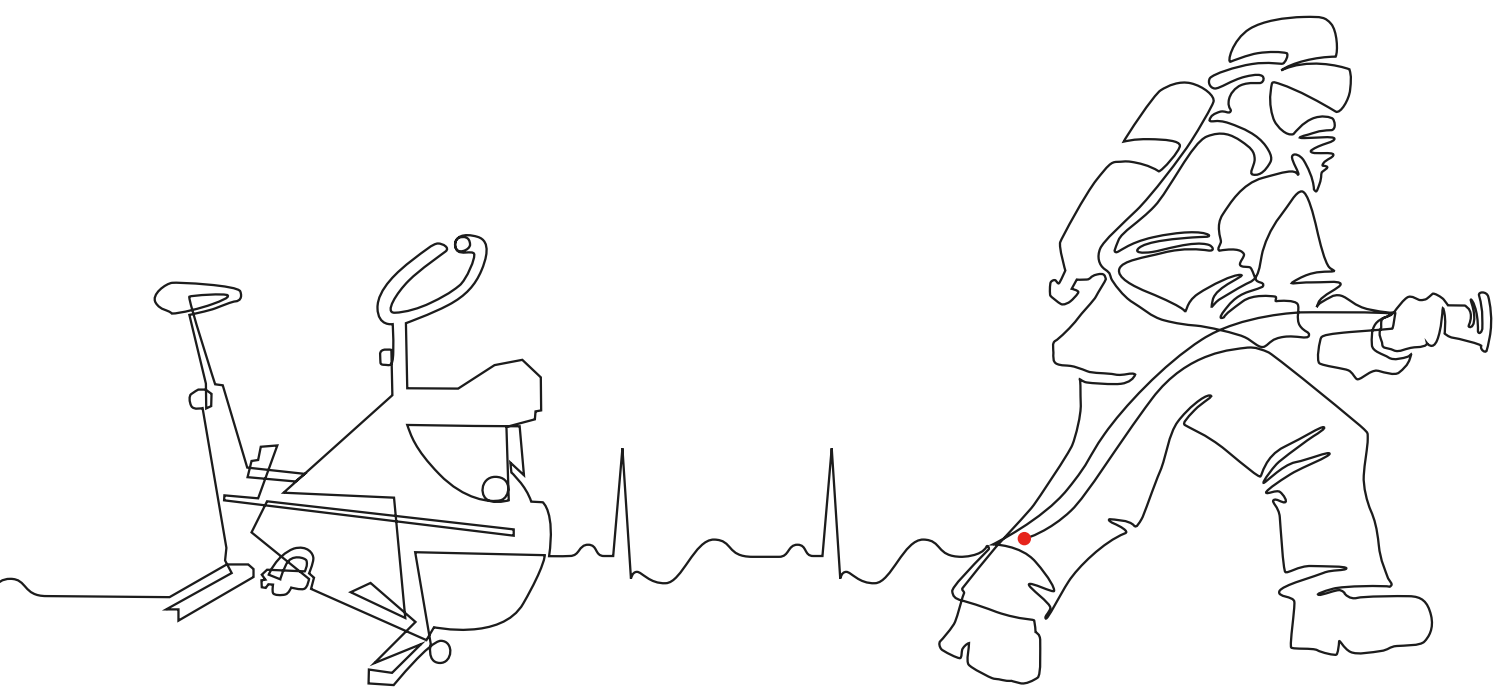


Linköping University Medical Dissertations No. 1688

\title{
Exercise Testing in Firefighters
}

Work Capacity and Cardiovascular Risk Assessment in a Low-Risk Population

\author{
Anna Carlén
}

Department of Medical and Health Sciences

Linköping University, Sweden

Linköping 2019 
(c)Anna Carlén, 2019

Cover illustration: Martin Nihlén

Published articles have been reprinted with the permission of the copyright holder.

Printed in Sweden by LiU-Tryck, Linköping, Sweden, 2019

ISBN 978-91-7685-046-6

ISSN $0345-0082$ 
To our children

Nils and Ebbe

Prediction is very difficult

especially about the future

Niels Bohr 



\section{CONTENTS}

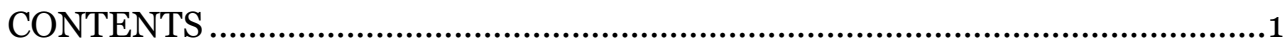

POPULÄRVETENSKAPLIG SAMMANFATTNING (in Swedish) ....................... 3

ABSTRACT ................................................................................................. 7

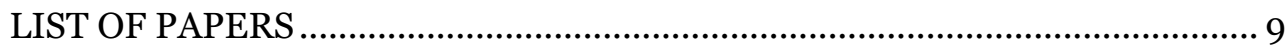

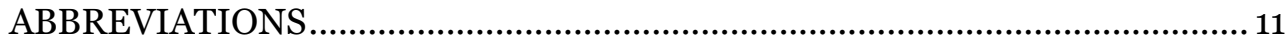

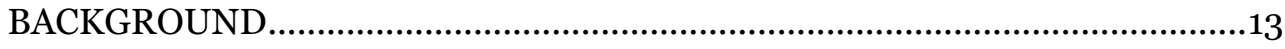

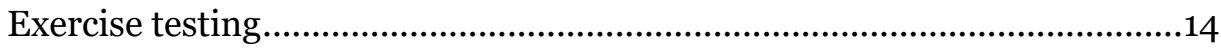

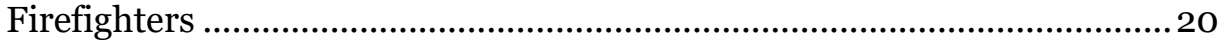

Background to research questions............................................................ 23

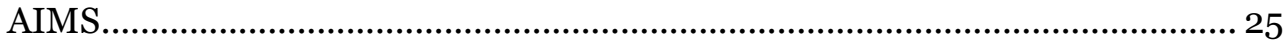

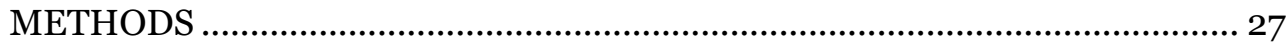

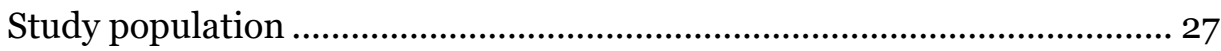

Exercise tests ................................................................................................31

Concepts of test interpretation ...................................................................... 37

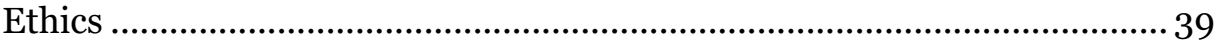

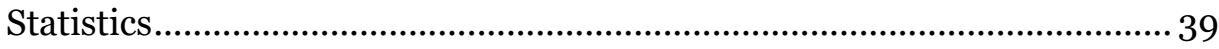

RESULTS .............................................................................................41

Exercise capacity ...........................................................................................41

Acquisition and processing of ExECG data ...............................................46

Identification of IHD ................................................................................... 48

Abnormal ExECG in the absence of IHD ..................................................... 54

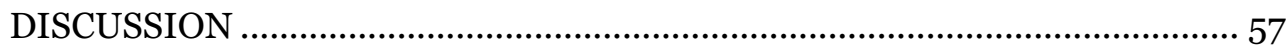

Evaluation of exercise capacity ……............................................................. 57

Exercise testing for identification of subclinical IHD in low-risk

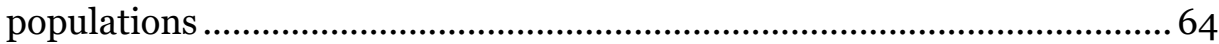

ST depression in the absence of known CAD …………................................ 70

Methodological limitations ....................................................................... 72

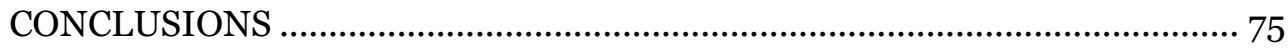

CLINICAL IMPLICATIONS AND FUTURE PERSPECTIVES...........................77

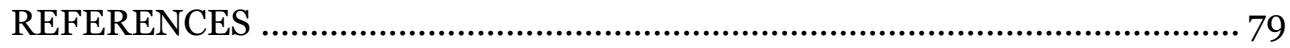

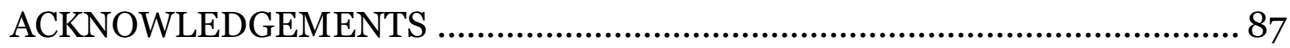




\section{POPULÄRVETENSKAPLIG SAMMANFATTNING}

Brandmän utsätts i sitt yrke för hårda fysiska påfrestningar, i synnerhet under rök- och kemdykning. Förutom brandbekämpning, räddning av människor i fara och andra krävande uppgifter som tillhör räddningsarbetet, ställer tung skyddsutrustning, värmebelastning och psykologisk stress stora krav på brandmannens fysiska förmåga. För att klara av arbetsmomenten på ett effektivt och säkert sätt är det därför viktigt att säkerställa att varje enskild brandman har tillräckligt god kondition och hälsa.

Det är enligt Arbetsmiljöverkets föreskrifter reglerat att brandmän ska konditionstestas och screenas för hjärtsjukdom vid upprepade medicinska tjänstbarhetsbedömningar. Arbetsprov med EKG-registrering, utfört till maximal ansträngning på testcykel, används för riskbedömning av eventuell bakomliggande hjärtsjukdom. Tidigare undersöktes även konditionen på testcykel genom ett 6 minuter långt test med konstant belastning (200 watt). För att testa brandmännen på ett mer yrkesspecifikt sätt omarbetades konditionstestet och sedan 2008 används enbart konditionstest på rullband, där brandmannen iklädd full rökdykarutrustning (24kg), måste klara 6 min i viss hastighet och lutning.

De båda testerna antas på gruppnivå ha jämförbara syreupptagningskrav, men skiljer sig arbetsfysiologiskt åt. Cykelprov har relativt konstant mekanisk verkningsgrad och en viss belastning kräver ungefär samma absoluta syreupptag för olika individer. Vid rullbandsarbete är den mekaniska verkningsgraden däremot inte konstant och ett flertal faktorer påverkar syreförbrukningen, i synnerhet testpersonens egen kroppsvikt.

Arbetsprov med EKG-registrering är en relativt billig och enkel metod, som traditionellt bedömer sannolikheten för kranskärlssjukdom genom att analysera EKG-komplexets ST-sträcka vid maxarbete. Testets möjligheter att upptäcka eller utesluta kranskärlssjukdom varierar dock i olika grupper beroende på olika förekomst av hjärtsjukdom. I grupper med låg sannolikhet för sjukdom, dit yrkesverksamma brandmän kan antas höra, uppstår ofta tolkningsproblem på grund av stor andel falskt positiva 
resultat, d.v.s. ST-sänkning kan uppstå även hos personer utan bakomliggande kranskärlssjukdom.

Genom att kombinerat studera puls- och ST-utveckling (ST/HR) under provets arbets- och återhämtningsfas, kan ett flertal utvidgade parametrar beräknas (ST/HR index, ST/HR slope samt area och rotationstyp för ST/HR loopen). ST/HR har i tidigare studier visat sig användbart för både diagnostik och sjukdomsgradering av kranskärlssjukdom i vissa grupper.

Syftet med studierna i den här avhandlingen var att

- undersöka hur individuella faktorer såsom kroppskonstitution påverkar sannolikheten att klara de olika konditionstesterna, samt att jämföra uppmätt puls och beräknat syreupptag från respektive test.

- utarbeta en metod för att extrahera och kvalitetssäkra data från ett kliniskt arbetsprovssystem till att användas för forskningsändamål.

- studera värdet av ST- och ST/HR-parametrar vid analys av arbetsEKG på friska, symtomfria individer.

- karaktärisera faktorer som är kopplade till utveckling av STsänkning hos personer utan känd kranskärlssjukdom.

Vi har studerat rullbandstest och arbets-EKG genomförda 2004-2011 av brandmän inom Räddningstjänsten i Östergötland. För brandmän som gett sitt samtycke har vi också genom journalstudier följt upp resultat av hjärtundersökningar och förekomst av eventuell hjärtsjukdom fram till och med 2015 .

Vid jämförelse av test på rullband och cykelergometer fann vi att trots att rullbandstestet tycktes mer krävande, med tanke på både högre slutpuls och högre beräknad syreåtgång, var det vanligare att klara rullbandstestet och samtidigt inte uppfylla kravet på cykeltestet, än vice versa. Längre och yngre brandmän hade ökad sannolikhet att klara båda testtyperna, medan lägre kroppsvikt enbart var en fördel vid rullbandstestet.

Vidare fann vi att utveckling av ST-sänkning under arbete var vanligt (20\%) hos dessa symtomfria brandmän, medan insjuknande i ischemisk hjärtsjukdom under uppföljningstiden var låg (2\%). Avvikande resultat vid fördjupad EKG-diagnostik med ST/HR analys var associerad med ischemisk hjärtsjukdom i fler EKG-avledning än vad ST-sänkning var, i synnerhet för de variabler som inkluderade både arbets- och återhämtningsfas i kombination.

ST-sänkning i samband med fysiskt arbete hos personer utan känd hjärtsjukdom var associerat med stigande ålder. Dessutom fanns en kopp- 
ling mellan ST-sänkning och stor pulsökning. Vi fann däremot inget samband mellan ST-sänkning och traditionella riskfaktorer för kranskärlssjukdom (högt blodtryck, höga blodfetter och diabetes).

Sammanfattningsvis innebär dessa resultat att man genom bytet av metod för konditionstest av svenska rökdykande brandmän, från cykelergometer till rullband, kan ha sänkt miniminivån för godkänd kondition. Visserligen kan rullbandstestet ha fördelar genom att vara mer yrkesspecifikt, men det är det oklart huruvida den ändrade kravprofilen påverkar yrkesutövningen.

Vid tolkning av arbetsprov på symtomfria personer kan ST/HR analys övervägas. Däremot var andelen falskt positiva och falskt negativa resultat fortfarande så hög vid ST/HR-analys, att värdet av arbetsprov för att hitta kranskärlssjukdom hos symtomfria brandmän och andra motsvarande grupper är mycket tveksamt. 
Exercise testing in firefighters 


\section{ABSTRACT}

Background. Firefighting is one of the most physically demanding occupations and it requires a high cardiorespiratory fitness level.

Pre-duty medical evaluation of firefighters includes fitness testing and assessment of cardiac health to ensure that firefighters meet the minimum physical fitness standard and to ensure that they are not at increased risk of cardiac events. The medical evaluation methods for Swedish firefighters are regulated by the Swedish Work Environment Authority and include a 6 min constant workload treadmill (TM) test for fitness evaluation in which the firefighter wears full smoke diving equipment and a maximal effort exercise electrocardiography test (ExECG) at cycle ergometer (CE) for assessment of cardiac health. Previously, fitness was also evaluated by cycle ergometry.

The standard parameter for evaluation of ischaemic heart disease (IHD) is exercise-induced ST depression. In general, exercise testing of asymptomatic low-risk individuals is discouraged due to low sensitivity and specificity for IHD, generating both false-positive and false-negative test results. Heart rate (HR) adjustment of the ST-segment response has been shown to be superior to simple ST depression to evaluate cardiac ischaemia in some populations, but has not been extensively evaluated in an occupational setting.

Methods. We retrospectively analysed a cohort of 774 firefighters who were asymptomatic at the time of the testing.

In paper I, test approval, HR response, and calculated oxygen uptake from TM tests and CE tests for 424 firefighters ( $44 \pm 10$ years) were compared.

Paper II methodologically described the process for data extraction, processing, and calculation of ExECG data from a clinical database. Procedures for noise assessment, error checking, and computerized calculation of ST/HR parameters were described.

In paper III, ExECG and medical records of 521 male firefighters ( $44 \pm 10$ years) were studied. During $8.4 \pm 2.1$ years of follow-up, IHD was verified angiographically in 12 subjects. The predictive value of HRadjusted ST variables (ST/HR index, ST/HR slope, and ST/HR loop) for IHD was evaluated. 
In paper $I V$, subjects with objectively verified IHD were excluded and factors associated with exercise-induced non-ischaemic ST depression were studied in the remaining 509 males ( $46 \pm 11$ years).

Results. The firefighters had an average maximal exercise capacity of $281 \pm 36 \mathrm{~W}$ (range 186-467 W) achieved by incremental CE exercise. To enable comparison, the maximal workload was converted to the workload sustainable for $6 \mathrm{~min}$. It was more common to pass the 6 min TM fitness test but to fail the supposedly equivalent $\mathrm{CE}$ test rather than vice versa.

Twenty percent of the firefighters developed an ST depression of $\geq 0.1$ $\mathrm{mV}$ in at least one lead during exercise and half of the firefighters had a horizontal or downsloping ST depression. While an abnormal ST response associated with an increased risk for IHD only in V4, both an abnormal ST/HR index and an abnormal ST/HR slope associated with IHD in three leads each. Clockwise rotation of the ST/HR loop was infrequent in all precordial leads (1\%), but it associated with an increased risk for IHD.

In the subgroup without evidence of coronary artery disease, age and the HR response associated with ST depression, whereas hypertension, hyperlipidaemia, diabetes, blood pressure response, and exercise capacity did not.

Conclusions. Even though the calculated oxygen uptake was higher for the TM test than for the supposedly equivalent CE test, the higher treadmill approval rate may indicate that the fitness requirement for Swedish firefighters has been lowered by changing the test modality.

Exercise-induced ST depression was common in asymptomatic physically active men, although there were only a few cases of IHD during follow-up. If performing ExECG in asymptomatic, low-risk populations, ST/HR analysis could be given more importance. However, the limited clinical value of ExECG in low-risk populations was emphasised and needs to be reconsidered.

In asymptomatic, physically active men without coronary artery disease, false-positive ST depressions can be partially explained by HR variables rather than by common cardiovascular risk factors and blood pressure response to exercise. 


\section{LIST OF PAPERS}

I. Loaded treadmill walking and cycle ergometry to assess work capacity: a retrospective comparison of 424 firefighters

A Carlén, M Åström Aneq, E Nylander, M Gustafsson

Clin Physiol Funct Imaging. 2017 Jan;37(1):37-44

II. Data acquisition for hypothesis testing from a clinical exercise electrocardiographic database

A Carlén, E Nylander, M Åström Aneq, M Gustafsson

Submitted

III. ST/HR variables in firefighter exercise ECG - relation to ischemic heart disease

A Carlén, E Nylander, M Åström Aneq, M Gustafsson

Physiol Rep. 2019 Jan;7(2):e13968

IV. Exercise-induced ST depression in the absence of coronary artery disease

A Carlén, M Gustafsson, M Åström Aneq, E Nylander

Scand Cardiovasc J. 2019 Aug;53(4):206-212 


\section{ABBREVIATIONS}

ACC American College of Cardiology

ACS Acute Coronary Syndrome

AHA American Heart Association

BMI Body Mass Index

BP Blood pressure

CA Coronary Angiography

CAD Coronary Artery Disease

CCTA Coronary Computed Tomography Angiography

CE Cycle ergometer

CVD Cardiovascular disease

CWL Constant Workload

ECG Electrocardiography

ExECG Exercise Electrocardiography

HR Heart Rate

IHD Ischaemic Heart Disease

MPI Myocardial Perfusion Imaging

LVH Left Ventricular Hypertrophy

PPV Positive Predictive Value

SD Standard Deviation

TM Treadmill

$\mathrm{VO}_{2} \quad$ Oxygen uptake

W Watt

WHO World Health Organization 


\section{BACKGROUND}

Physical activity increases the metabolic demand of the body more than anything else. The working skeletal muscles convert stored energy to muscular contractions to perform various kinds of external movements. This increased energy turnover requires an increased oxygen supply to enable aerobic cellular respiration and sustained work.

To meet the increased oxygen demand, both respiration and transport of oxygenated blood throughout the circulatory system are increased, which, in turn, requires increased pumping of the heart.

From rest to maximal effort, the heart rate (HR) can increase up to four-times, and the volume of blood pumped from the left ventricle with each heart beat can increase approximately 50\%, leading to an overall sixfold increase in the cardiac output.

\section{Oxygen supply to the cardiac muscle}

The coronary arteries are the vessels that distribute oxygenated blood and nutrients to the myocardium. Because the anaerobic capacity of the heart is limited, the cardiac response to exercise requires an instant increase in the oxygen supply to the myocardial tissue.

The vascular resistance of the coronary arteries is continuously regulated to deliver sufficient quantities of oxygen to meet changes in the demand. In addition, the myocardium extracts $70-80 \%$ of the delivered oxygen, which is higher than any other human organ. Consequently, additional extraction of oxygen as a response to increased demand is rather limited. Instead, an increase in the oxygen supply depends primarily on enhanced blood flow.

The regulation of the coronary circulation is complex. Several mechanisms modulate coronary vascular resistance, including extravascular compressive forces (tissue pressure), coronary perfusion pressure, myogenic, local metabolic, endothelial, hormonal, and direct and indirect neural factors [1].

In summary, a sufficient cardiac oxygen supply during exercise relies on the ability of the coronary arteries to dilate adequately to generate functional hyperaemia and to provide adequate amounts of oxygen by the increased blood flow. 


\section{Coronary artery disease (CAD)}

Coronary arteries exposed to cholesterol and inflammation will harden and narrow due to lipid deposition and plaque formation in a process called atherosclerosis, which leads to CAD. The main risk factors for atherosclerosis and $\mathrm{CAD}$ are dyslipidaemia, hypertension, diabetes, obesity, and smoking. All of these factors contribute to an inflammatory and prothrombotic environment in which oxidative stress and endothelial dysfunction trigger development of atherosclerotic lesions [2-4].

Atherosclerotic arteries are less able to increase blood flow in response to exercise, and the limitation depends on the degree and distribution of the restricting stenosis. If blood flow during rest or exercise is impeded such that the availability of oxygen does not meet the need, the affected subject may suffer chest pain (angina). With more advanced atherosclerosis and more limited blood flow, less activity is needed to provoke symptoms. Nevertheless, individuals with stenotic lesions that significantly reduce the size of the artery lumen may have no symptoms.

Eventually, an atherosclerotic plaque may rupture and the subsequent thrombus that covers the lesion can obstruct or occlude the artery leading to an acute coronary syndrome (ACS), such as myocardial infarction, unstable angina, or even sudden cardiac death (SCD).

In the papers included in this thesis, both the terms CAD and ischaemic heart disease (IHD) have been used to describe the disease of insufficient oxygen supply to the cardiac muscle. CAD and IHD essentially describe the same phenomenon and can often be used interchangeably even though they reflect morphological versus functional points of view.

\section{Exercise testing}

Because the requirements of the entire cardiorespiratory system increase with physical activity, an exercise test can reveal signs or symptoms of disease that are not present at rest. That is the main purpose of diagnostic exercise testing. Symptoms during exercise can originate from diseases in different organ systems, including the heart, the lungs, the peripheral circulation, the muscles, and the metabolism. Nevertheless, in the clinical setting, cardiac disease, especially suspected IHD, has been the single most common reason for exercise testing for almost a century.

Another aspect of exercise testing is evaluation of the cardiorespiratory fitness of the test subject. Fitness can be measured as the maximal oxygen uptake, maximal external work (watts, W), or maximal increase in energy expenditure by the end of the working phase compared to the rest phase (metabolic equivalent of task, MET). Knowledge of physical capacity can be used for a variety of contexts and circumstances ranging from 
the suitability to go through major surgery to the refinement of sports performance. Within certain areas of occupational medicine, exercise testing is also used to ensure a minimum level of exercise capacity to safely meet the demands of the work tasks.

\section{Exercise electrocardiography (ExECG)}

The reference and standard method for visualising the coronary vasculature and diagnosing CAD is coronary angiography. However, it is an invasive procedure associated with both risks and costs. ExECG is a noninvasive, relatively inexpensive, widely available, and generally safe technique. During physical exercise, electrocardiography (ECG) recordings are made and dynamic and morphological changes in the different ECG leads are analysed to identify patterns characteristic of exercise-induced ischaemia and to diagnose IHD.

During a standard exercise test procedure, ECG recordings are collected during exercise and during the subsequent recovery. Valuable information can be retrieved from all parts of the ECG recording, but for evaluation of IHD, the main area of interest is the ST segment (Fig. 1).

\section{ST depression}

During an ECG recording, depolarisation in the cardiac ventricles is reflected as a QRS complex. The subsequent ventricular repolarisation is seen as a T wave. Between the QRS complex and the T wave, the membrane potential of the myocytes is relatively constant, which is depicted as a nearly flat ST segment at the same level as the isoelectric PQ segment. The J point represents the time-voltage coordinate at the end of the QRS complex and at the beginning of the ST segment (Fig. 1).

During ischaemia, the membrane potential of the affected myocytes is altered. Hypoxia most often affects the innermost part of the cardiac muscle, the endocardium, where blood flow is functionally more restricted by increased pressure during cardiac contraction. The epicardial cells are located more favourably for oxygenation via the arteries that run along the outer surface of the heart, thus they can maintain normal function during partial reduction of the oxygen supply. The consequence is subendocardial ischaemia that results in an electrical difference in membrane potential between the endocardial and epicardial cells, which is visualised as an ST depression by the exploring ECG lead.

Although ST depression is typically caused by myocardial ischaemia, other physiological, pathological, and iatrogenic causes exist, such as digitalis treatment, hypokalaemia, intraventricular conduction abnormalities, and left ventricular hypertrophy [5, 6]. Normally, the QRS complex conceals the atrial repolarisation wave. During exercise with sinus tachycar- 
dia, the PQ interval is shorter and atrial repolarisation may coincide with the ST segment causing a deviation from the isoelectric level [7]. If atrial repolarisation occurs slightly earlier, it interacts with the $J$ point and drags it downwards, generating an upward-sloping ST depression.

The magnitude of the ST deviation is measured relative to the isoelectric baseline. At rest, the point of measurement is usually the $\mathrm{J}$ point. When the HR is increased, the $\mathrm{J}$ point may be physiologically depressed, and a more accurate point of measurement may be 60 or $80 \mathrm{~ms}$ after the $\mathrm{J}$ point (ST60 or ST80, respectively). In subjects with an elevated resting J point due to early repolarisation, the ST level generally approaches the isoelectric level with exercise, which is normal and should not be considered equivalent to an ST depression. Therefore, an ST depression should only be calculated as the additional negative deflection below baseline [8].

The most common electrocardiographical criterion for exerciseinduced ischaemia is a horizontal or downsloping ST-segment depression of at least 0.1 mV measured at ST6o or ST8o in one or several leads [9].

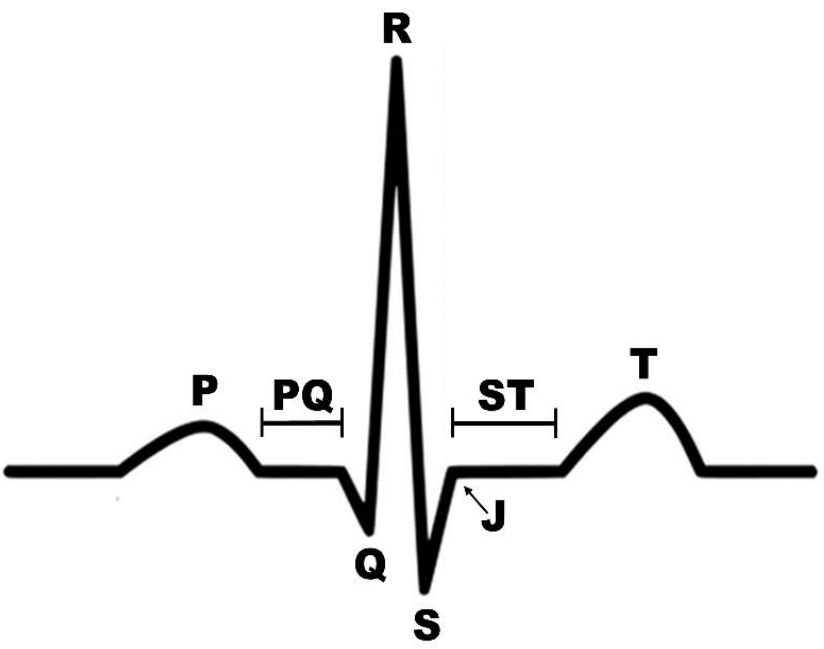

Figure 1. Example of an ECG recording with the different sections labelled. 


\section{Historical perspective}

Exercise testing for the detection of IHD was developed during the first half of the $2 \mathrm{O}^{\text {th }}$ century when the burden of cardiovascular mortality in the Western world was heavy.

As early as 1908, Einthoven, "the father of the electrocardiogram", recorded post-exercise ST depression in a patient [10]. During the following decades, it was correctly hypothesised that exercise-induced STsegment depression was caused by myocardial ischaemia. At the same time, the quality of electrocardiographic recording devices improved, which allowed for recording of precordial leads with higher sensitivity for IHD detection [11].

The role of ExECG for the diagnosis of CAD was initially very promising. Later, correlation of ExECG data with angiographic findings revealed limitations in ExECG methodology [12] and raised questions on the optimal use of the ExECG. For example, the correlation between an abnormal ExECG and CAD has been shown to be low in asymptomatic subjects [13].

In 1989, a well-cited meta-analysis studied the standard ST depression criterion in over 24,000 subjects and found a mean sensitivity for IHD of $68 \%$ (range 23-100\%) and a mean specificity of 77\% (range 17100\%) [14]. The wide ranges were due to differences in the characteristics of the populations studied and other methodological factors.

More recent studies and guidelines have emphasised the importance of pre-test probability evaluations to determine the value of the test results $[9,15]$. In summary, the probability of a "true" positive stress test depends on the pre-test risk of the patient.

Thus, it has become clear that, although evaluation of exerciseinduced ST depression is the most widely used, and most studied parameter for analysis of suspected CAD, its usefulness is limited due to its low sensitivity and poor positive predictive value in low-prevalence populations. This insight is important because the prevalence and mortality of cardiovascular disease in the Western world has decreased [16].

According to the 2013 European guidelines on management of stable $\mathrm{CAD}$, exercise testing is discouraged in low-risk groups $(<15 \%$ pre-test probability) [17].

\section{ST/HR analysis}

Improved approaches to analyse ExECGs beyond simple analysis of ST depression are sought after. The rationale behind the HR correction of the ST depression is the relationship between HR and ST depression during exercise-induced ischaemia. HR normally increases in proportion to 
the myocardial oxygen demand during exercise. Thus, in the case of blood flow limitation, the HR can be expected to correlate with the onset and severity of ischaemia. Exercise-induced ST depression is dependent on the presence of a coronary obstruction and on the amount of additional myocardial oxygen required for increased work. Therefore, there should be a relationship between the degree of ST depression and HR increase in CAD cases. Instead of only evaluating the ST depression at peak exercise, this methodology adds a dimension to the ST assessment and theoretically enables identification of CAD in cases with a subthreshold ST depression $(<0.1 \mathrm{mV})$.

The two original methods for HR correction of the ST depression were ST/HR slope and ST/HR index (Fig. 2).

ST60 $(\mu \mathrm{V})$

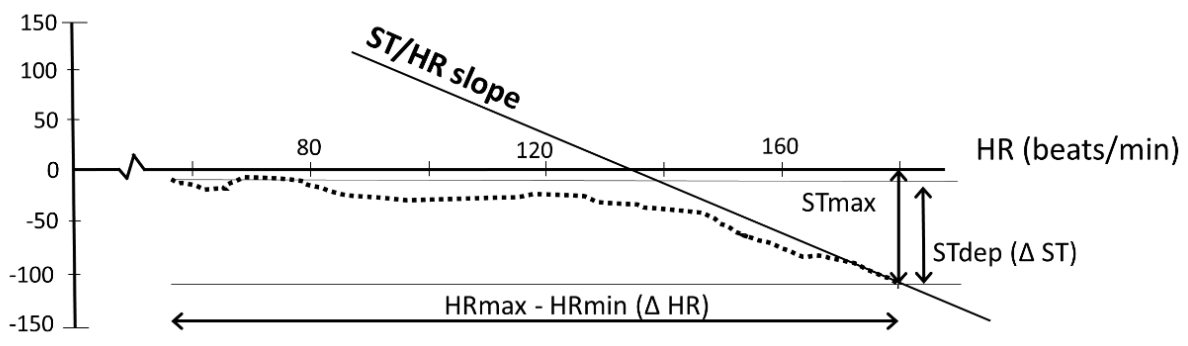

$S T / H R$ index $=\Delta S T / \Delta H R$

Figure 2. Principles for calculating the ST/HR index and the ST/HR slope.

$\mathrm{HR}=$ heart rate, STdep $=$ ST depression

\section{ST/HR slope}

The ST/HR slope represents the peak rate of ST-segment change as a function of HR during the end of the exercise phase. Analysis begins by calculating a regression line using at least the final three ST/HR pairs during the exercise phase and progressively includes the previous ST/HR pairs. The steepest significant regression line $(p<0.05)$ is accepted as the ST/HR slope for that lead. In the original publication, the value from the lead with the greatest ST/HR slope was used as the final test result [18].

The ST/HR slope was initially suggested to evaluate the severity of IHD and could accurately predict the presence and severity of CAD in patients with anginal pain [19]. Later, other investigators confirmed higher CAD sensitivity for the ST/HR slope in study populations referred for coronary angiography because of suspected CAD [20]. 


\section{$S T / H R$ index}

The ST/HR index is mathematically simpler then the ST/HR slope and divides the overall ST depression by the HR increase during exercise [21]. Theoretically, it is an attractive and easily available approximation of the ST/HR slope. Because healthy patients supposedly have relatively high HRs compared to sick patients, the ST/HR index in normal individuals should be lower than in subjects with heart disease.

In patients with non-significant ST depression $(\leq 0.1 \mathrm{mV})$, but with clinical stable angina or angiographically proven $\mathrm{CAD}$, an abnormal ST/HR index (see definition below) correctly identified $50 \%$ of patients with CAD [22]. However, another study that compared ST depression and the ST/HR index in patients referred for exercise testing due to suspected CAD did not find better results with the ST/HR index than with ST depression [23].

\section{Suggested cut-off levels for ST/HR variables}

In an early publication evaluating the HR correction of the ST depression, Kligfield et al. determined the ST/HR index and the ST/HR slope in a subgroup of normal subjects without anginal pain or abnormal coronary angiography findings. Partition values were identified by calculating the $95^{\text {th }}$ percentile values for the ST/HR slope and the ST/HR index in these subjects. Consequently, an ST/HR slope $\leq-2.4 \mu \mathrm{V} /$ beats/min and an ST/HR index $\leq-1.6 \mu \mathrm{V} /$ beats/min were defined as abnormal [24]. These partition values have been used in other studies [25].

\section{ST/HR loop}

Plotting all of the ST/HR pairs from the work and recovery phases generates an ST/HR loop that has been characterised in terms of rotation pattern [26] and area of ST/HR hysteresis [27].

In the Framingham offspring study that analysed asymptomatic men and women, the relative risk of coronary events was 1.9 when either the ST/HR index or the ST/HR loop was abnormal, and when both the ST/HR index and the ST/HR loop were abnormal, the relative risk of coronary events was 3.6, whereas the standard ST-segment depression criterion was not predictive of new coronary events [25].

\section{Exercise test modalities}

The two main modalities for exercise testing, with or without ECG registration, are cycle ergometer (CE) and treadmill (TM). Both modalities engage large muscle groups in dynamic work to generate a large increase in oxygen uptake for evaluation of aerobic capacity and possible IHD. Inter- 
nationally, TM testing is often the standard for exercise testing, whereas the Scandinavian tradition favours cycling.

Pedalling elicits a cardiorespiratory response closely associated with the resistance that has to be overcome to keep the pedals and the wheel moving. Advantages of $\mathrm{CE}$ are that the relatively constant mechanical efficiency of the work performed is not particularly affected by body composition [28] and that the work correlates fairly well with the absolute oxygen uptake required for a given load [29]. On the other hand, the metabolic demand of TM exercise is largely affected by the body mass that has to be transported forwards and upwards, hence mechanical factors inherent in the testing, such as speed and grade, alone do not associate with specific oxygen uptake.

\section{Firefighters}

Firefighters have one of the most physically demanding occupations. At the emergency scene, they perform a variety of tasks, including connecting hose lines to hydrants, positioning and climbing ladders, and rescuing victims, which all involve lifting, carrying, and pulling heavy objects in hot and hazardous environments. The work is performed while carrying the additional weight of the personal protective equipment and the selfcontained breathing apparatus (SCBA), which, in itself, requires extra work. In addition to the physiological stress, the emotional stress and the heat stress affect the cardiorespiratory response. Firefighting activities elicit HRs near or at the age-predicted maximum [30] indicating a substantial strain on the cardiovascular system. Thus, a high cardiorespiratory fitness level is required to manage many of the strenuous tasks associated with fire suppression and search and rescue.

Among U.S. firefighters, on-duty mortality is related to cardiovascular disease (CVD) in about $45 \%$ of the cases, which is higher than among other emergency personnel. Research has shown that most firefighter onduty CVD fatalities are elicited by the work and occur in firefighters with underlying CAD [31]. The Swedish fire brigade is substantially smaller and has lower absolute numbers of deaths. Swedish authorities do not keep data on disease prevalence or fatal incidents among firefighters, although deadly accidents seem to be more common than death due to CVD [32].

\section{Aerobic demands of firefighting}

It is difficult to measure the actual oxygen cost of firefighting due to the limitations of the measuring instruments in strong heat and smoke and the potentially disruptive effects of the instruments on fire suppression 
when public safety is at risk. Therefore, the oxygen requirement of firefighting has normally been estimated or directly measured under simulated firefighting conditions.

A study of oxygen consumption in typical firefighting activities showed an average oxygen requirement of $23 \mathrm{ml} / \mathrm{kg} / \mathrm{min}$ for $90 \%$ of the most common tasks [33]. However, the most demanding operations required more than $42 \mathrm{ml} / \mathrm{kg} / \mathrm{min}$ [33, 34]. Other studies on simulated firefighting have found average oxygen consumption values to be 29-34 $\mathrm{ml} / \mathrm{kg} / \mathrm{min}\left[35^{-38}\right]$.

\section{Recommendations on minimum fitness level}

In the literature, for firefighters, minimum aerobic capacity recommendations vary between 39 and $45 \mathrm{ml} / \mathrm{kg} / \mathrm{min}[33,35,39]$ and absolute oxygen uptake recommendations range from $2.7 \mathrm{l} / \mathrm{min}$ [39] to $4.0 \mathrm{l} / \mathrm{min}$ [40].

It is worth noting that the SCBA used during smoke diving reduces the maximal oxygen uptake significantly [41]. Therefore, a margin is required when work-related activities are assessed without a breathing apparatus. The need for a margin is also strengthened by the finding that a self-selected pace of about $85 \%$ of the maximal oxygen uptake $\left(\mathrm{VO}_{2} \max \right)$ was chosen when firefighters were asked to perform a task as quickly as possible [36]. This indicates that a high maximal aerobic capacity is required to manage certain tasks and also contributes to the safety of the firefighters and the victims because the rescue work can be completed in a shorter time.

\section{Regulations and requirements}

Exercise tests of firefighters are intended to assess work capacity and to ensure a sufficiently high oxygen uptake to fulfil firefighting duties in a safe way. According to current regulations that have been valid since 2006, all Swedish firefighters must undergo an annual medical examination to be approved for smoke diving duty (search and rescue). The medical evaluation requires a TM fitness assessment and CE ExECG testing [42].

The ExECG testing is performed with increasing workloads until exhaustion is reached, and the primary aim of ExECG testing is to screen for IHD. With increasing age, the time interval between ExECG tests decreases. Initially, ExECG testing is repeated every 5 years, but between the ages of 40-50 years, testing is performed every 2 years, and after 50 years of age, ExECG tests are performed annually.

Fitness requirements for Swedish firefighters were first introduced in 1986. Initially, work capacity was evaluated by CE with a $200 \mathrm{~W}$ constant workload (CWL) test for $6 \mathrm{~min}$, requiring an oxygen uptake of at least 2.8 
L/min [43]. However, fire personnel and researchers criticised the original CE test for not accurately reflecting the occupational demands, including the heavy equipment and the bodyweight that the firefighter carries. Therefore, in 1995, a TM test was introduced as an alternative to the CE test, and the new TM test consisted of walking while wearing $24 \pm 0.5 \mathrm{~kg}$ of personal protective equipment for $6 \mathrm{~min}$ on an $8^{\circ}$ elevated slope at 4.5 $\mathrm{km} / \mathrm{h}$ or faster (Fig. 3). Since 2008, the TM test has replaced the CE test and is now compulsory for the annual evaluation of work capacity in Swedish firefighters [42].

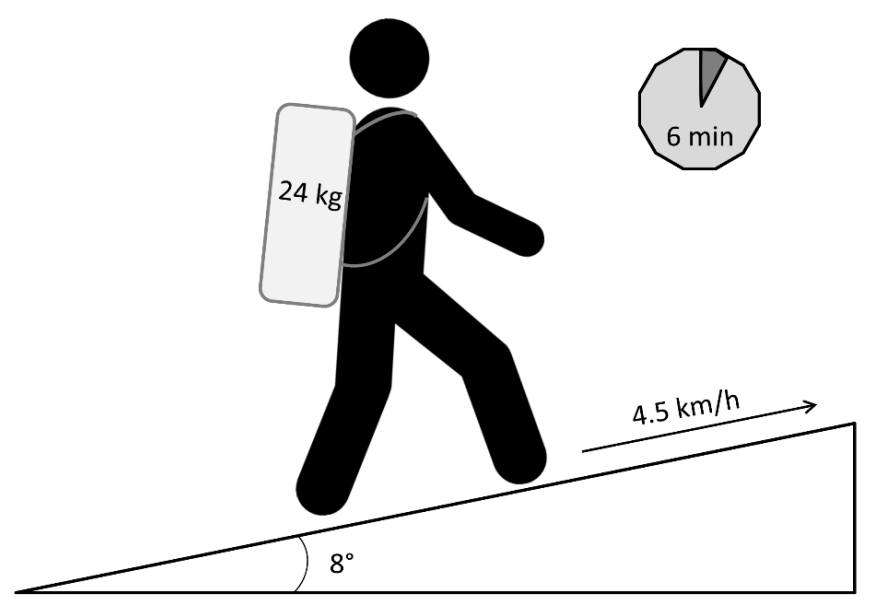

Figure 3. Schematic illustration of the TM test. 


\section{Background to research questions}

There is little doubt that firefighting is physically demanding. Together with occupational skills, adequate fitness is necessary to perform emergency operations with as little risk as possible for the individual firefighter, his or her colleagues, and potential fire victims. In Sweden, the test modality for the fitness assessment has changed over time from a standard bicycle ergometer test to a more occupational-specific TM-based test with an added burden and heat stress from the turn-out gear. The differences in the cardiovascular requirements between the two tests have not been studied previously.

Although exercise testing for the assessment of CAD is discouraged in low-risk subjects [17], official regulations require that Swedish firefighters perform repeated ExECG tests prior to smoke diving duty [42].

The diagnostic and prognostic value of exercise testing in asymptomatic populations has been studied extensively for many decades. The vast majority of ExECG studies have focused on simple ST depression analysis at maximum work [44] even though other exercise-related variables have gained attention as both diagnostic markers and prognostic indicators $[45,46]$. If an in depth ECG analysis, including ST deviation in relation to HR during both exercise and recovery (ST/HR analysis), could increase the sensitivity and specificity of the ExECG, it could be more valuable as a diagnostic tool, also in asymptomatic populations and firefighter recruits.

Because of the low specificity of ExECG in asymptomatic populations, a substantial proportion of tested firefighters would be expected to exhibit exercise-induced ST depression despite the absence of CAD. An enhanced knowledge of factors that contribute to such a response in low-risk individuals could improve understanding of the test results. 


\section{AIMS}

The aim of the work described in this thesis was to study exercise testing in a cohort with low CVD risk and a high fitness level relative to the general population. More specifically, the aims were to evaluate two exercise test modalities used to assess the fitness of firefighters and to identify associations between ExECG test results and subclinical IHD in a low-risk population.

The objectives were:

- To compare measured and calculated indicators of cardiovascular demand as well as the calculated work, between a CE test and a firefighter-specific TM test.

Paper I

- To investigate how individual factors, such as body composition, affect test approval of two exercise test modalities.

Paper I

- To describe the methodological steps taken to acquire reliable research data from a large clinical exercise test database.

Paper II

- To evaluate the ability of exercise-derived electrocardiographical parameters, specifically ST depression and HR-adjusted ST variables, to correctly identify IHD in asymptomatic low-risk subjects.

Paper III

- To characterise factors in the cardiovascular response to exercise that associated with exercise-induced ST depression in asymptomatic men without CAD.

Paper IV

- To evaluate the association between risk factors for IHD and exercise-induced ST depression in asymptomatic men without CAD.

Paper IV 


\section{METHODS}

\section{Study population}

All full-time and part-time firefighters in the Swedish county of Östergötland who had performed at least one CE exercise test between January 2004 and December 2010 ( $n=774)$ could initially be included in these studies.

A letter was sent to all of the firefighters asking for informed consent to review their medical records for cardiac disease along with a short questionnaire asking for additional health care information, such as dates and locations of additional health care facilities where cardiac disease tests and treatments were performed. A reminder was sent after two months if no reply was received.

\section{Paper I}

TM tests were carried out at the local fire stations. TM test results were collected retrospectively and were added to the study database. In some cases, only the most recent test results were available, but if a test was dated later than December 2010, it was excluded from the study. Tests with missing body weight or test date data were not included. At least one $\mathrm{CE}$ and one TM test from the inclusion period that met the inclusion criteria were available for 424 firefighters (97\% males) (Fig. 4).

\section{Paper II}

Paper II describes the methodology used for extracting and processing ExECG data for papers III-IV.

\section{Paper III}

Informed consent to access county medical records was obtained from 567 male firefighters. Significant gender differences have previously been shown for ExECG performance and the identification of IHD [47]. Because the proportion of females in this study population was too small (3\%) for subgroup analysis of ExECG variables, they were excluded from further analysis.

According to predefined exclusion criteria (Table 3) that could hamper interpretation of ST/HR data, 29 males were excluded resulting in a study population of 521 male firefighters in paper III (Fig. 4). 


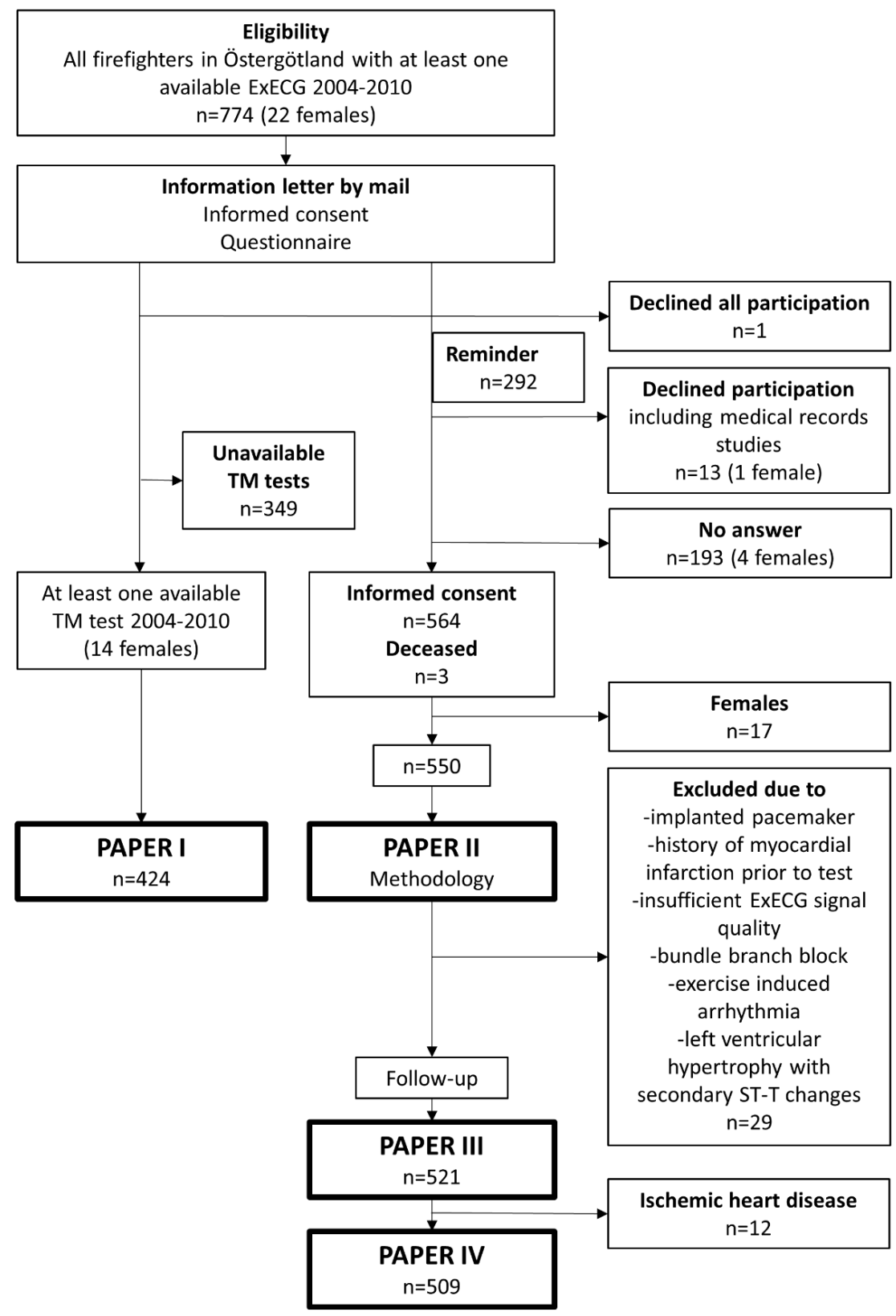

Figure 4. The study populations for the different papers. Note that subjects in paper I were available also for papers II, III, and IV. 


\section{Paper IV}

Paper IV aimed to characterize non-ischaemic ST depression, therefore all 12 subjects from paper III with objectively verified CAD were excluded and the remaining 509 individuals were included as subjects in paper IV (4).

\section{Characteristics}

Table 1 summarises the subjects included in papers I, III, and IV.

Table 1. Subjects included in papers I, III, and IV.

\begin{tabular}{llll}
\hline & Paper I & Paper III & Paper IV \\
\hline Number, n & 424 & 521 & 509 \\
Males, \% & 97 & 100 & 100 \\
Age, years & $44 \pm 10$ & $44 \pm 10$ & $46 \pm 11$ \\
Weight, kg & $86 \pm 11$ & $86 \pm 11$ & $86 \pm 10$ \\
Height, cm & $180 \pm 7$ & $181 \pm 6$ & $181 \pm 6$ \\
BMI, kg/m & $26 \pm 3$ & $26 \pm 3$ & $26 \pm 3$ \\
IHD during follow-up, $\mathrm{n}$ & $\mathrm{NA}$ & 12 & 0 \\
Employment & & & \\
Full-time, \% & 44 & 46 & 46 \\
Part-time, \% & 56 & 52 & 52 \\
Unknown, \% & 0 & 2 & 2 \\
\hline
\end{tabular}

$B M I=$ body mass index, $I H D=$ ischaemic heart disease

\section{Follow-up}

Informed consent to access county medical records was obtained from 550 male firefighters. Medical records up to June 2015 were examined for histories of cardiac disease and the following were searched for:

- Cardiac imaging studies (coronary angiography, myocardial scintigraphy, cardiac magnetic resonance imaging, and coronary computed tomography). Test results were classified as:

○ Normal

○ Inconclusive/non-significant IHD

○ Significant IHD

- Diagnoses within the circulatory system according to the World Health Organization (WHO) International Classification of Diseases (codes Ioo-I99), as well as diagnoses for diabetes (E10, E11, E14) and hyperlipidaemia (E78) [48]. During examination of medical 
records, each diagnosis was only registered in the study database the first time it was found for each individual.

- Mortality data for individuals who died during the follow-up period, including the date and cause of death. The cause of death was registered as:

o Cardiac

o Cardiac but non-ischaemic

$\circ$ Other

If there was a positive answer in the questionnaire regarding cardiac investigation and/or treatment performed outside the county $(n=3)$, a copy of the medical record was requested from the specified health care facility and the results were added to the study database.

\section{Loss to follow-up}

By December 2015 (six months after the end of the follow-up period), $96 \%$ of the study subjects who had consented to medical record review were still registered in the study county of Östergötland, thus their medical records were available for digital follow-up. The remaining $4 \%$ had moved outside the county $(n=25)$, emigrated $(n=1)$, or could not be retrieved from the census record for other reasons $(n=3)$. Among those registered outside of the county, almost two-thirds (64\%) were under 40 years of age and were considered to have a low likelihood for cardiac events.

In case a local inhabitant suffered a cardiac event outside the county, any aftercare or medical follow-up was assumed to be performed within the home county, thus it should have been included in the medical record review. 


\section{Exercise tests}

In these studies, both TM and CE tests were analysed.

\section{Treadmill (TM) tests}

The TM test consisted of a $1+1$ min warm-up period of walking at $2.5^{\circ}$ and $4^{\circ}$ inclines, respectively, followed by 6 min of walking at an $8^{\circ}$ incline. The TM speed was constant but ranged between 4.5 and $5.7 \mathrm{~km} / \mathrm{h}$ depending on age-adjusted local policies. According to the Swedish regulation for smoke diving firefighters, 6 min at a minimum speed of $4.5 \mathrm{~km} / \mathrm{h}$ at an $8^{\circ}$ incline was required for test approval of existing employees (Fig. 3), whereas $5.6 \mathrm{~km} / \mathrm{h}$ was required for new employees. Handrails were not allowed for support. The subjects wore full personal protective equipment with a total extra weight of $24 \pm 0.5 \mathrm{~kg}$, including a SCBA without the facial piece, and with light shoes instead of boots [42]. HR data were collected using a pulse watch with a chest strap, and HR data were recorded every minute or, at some fire stations, as peak HR only.

\section{Cycle ergometer (CE) tests}

CE tests were carried out on a computer-controlled, mechanically braked $\mathrm{CE}$ with a cadence-independent workload system (Ergomedic 839E, Monark, Vansbro, Sweden). Two test types were used during the study period: the CWL test for fitness assessment and the incremental ramp test for evaluation of maximal work capacity.

The CWL test included a 2 min warm-up at $100 \mathrm{~W}$ and 6 min at 200 $\mathrm{W}$. For testing of new recruits, $250 \mathrm{~W}$ was used. The CWL test immediately transitioned to the incremental ramp test with a successively increasing workload until exhaustion was reached.

During the incremental ramp test, the starting workload was chosen by the test leader depending on the expected final workload and ranged from 50 to $90 \mathrm{~W}$, and then the workload increased $1 \mathrm{~W}$ every $3 \mathrm{~s}(20$ $\mathrm{W} / \mathrm{min}$ ) continuously until exhaustion. The final power output $\left(\mathrm{P}_{\max }\right)$ was registered.

Workload and 12-lead ECG data, including HR, was monitored continuously during the CE test and blood pressure (BP) was measured every $3 \mathrm{~min}$. All of the CE tests were supervised by the same cardiologist. Tests were terminated prematurely if an adverse cardiovascular sign, such as arrhythmia or a pathological increase in the BP according to standard criteria, was observed. 


\section{Extraction and processing of exercise ECG data}

ExECG data before, during, and after pedalling were registered with a PCbased ExECG system (Welch Allyn Cardioperfect 1.6.3). The system stored important basic test data as the test progressed (Table 2). The dynamic variables of interest (ST variables and HR) were stored at $15 \mathrm{~s}$ intervals throughout the test and were recorded as the mean values of the past $15 \mathrm{~s}$.

All of the firefighter ExECG recordings performed between 2004 and 2010 were manually exported from a clinical database to a research database file.

ECG leads V1 and aVL were excluded from further analyses as suggested by Okin et al. [26] and adopted by several investigators because of insufficient diagnostic information [24, 27, 49-52].

Table 2. Variables stored in the ExECG database.

\begin{tabular}{ll}
\hline Variable & Comment \\
\hline TID & Unique test ID \\
DoB & Date of birth \\
DoT & Date of test \\
TP & Test protocol \\
Weight & Weight, recorded once before the first test $(\mathrm{kg})$ \\
Height & Height, recorded once before the first test $(\mathrm{cm})$ \\
MaxBP & Maximum registered blood pressure during the test $(\mathrm{mmHg})$ \\
HR & Heart rate (beats/minute) \\
Lead\# & Data assigned to a specific ECG lead \\
ST40 & ST level 40 ms from the J point $(\mu \mathrm{V})$ \\
ST60 & ST level 60 ms from the J point $(\mu \mathrm{V})$ \\
ST80 & ST level 80 ms from the J point $(\mu \mathrm{V})$ \\
Time & Time since the test started $(\mathrm{s})$ \\
Wmax & Maximum load achieved $(\mathrm{W})$ \\
Tend & Time at the shift from the work phase to the rest phase $(\mathrm{s})$ \\
\hline
\end{tabular}

$B P=$ blood pressure, $m s=$ milliseconds 


\section{Eligible tests}

On average, $2.5 \pm 1.7 \mathrm{CE}$ tests for each subject in the entire cohort were registered in the study database. For the subpopulation of subjects who consented to medical record follow-ups, tests were assessed for eligibility regarding ST and ST/HR parameters. Exclusion criteria that could hamper the automated interpretation of ST and ST/HR data included the following (Table 3):

- Conduction disorders at rest or during exercise (e.g. left or right ventricular bundle branch block)

- Arrhythmia at rest or during exercise (e.g. atrial fibrillation/flutter, prolonged supra ventricular tachycardia affecting the HR curve)

- Left ventricular hypertrophy with secondary ST deviations at rest

- $<3$ min recovery time

- Tests performed by pacemaker carriers

- Technically poor registration quality

- Other (e.g. prematurely ended test due to low grade infection, joint pain, etc.)

- Tests performed after diagnosis of IHD

Except for the subjects excluded due to the last criterion, none of the other subjects who were excluded due to the above criteria were diagnosed with IHD during follow-up.

Table 3. Overview of consecutive, available, and excluded ExECG tests independent of performance date. The first column includes the first available test for each study subject. For definitions of the exclusion criteria, see the text.

\begin{tabular}{lccccccc}
\hline Test \# & $\mathbf{1}^{\text {st }}$ & $\mathbf{2}^{\text {nd }}$ & $\mathbf{3}^{\text {rd }}$ & $\mathbf{4}^{\text {th }}$ & $\mathbf{5}^{\text {th }}$ & $\mathbf{6}^{\text {th }}$ & $\mathbf{7}^{\text {th }}$ \\
\hline Eligible & $\mathbf{5 0 2}$ & $\mathbf{3 1 2}$ & $\mathbf{2 0 2}$ & $\mathbf{1 2 9}$ & $\mathbf{6 8}$ & $\mathbf{4 2}$ & $\mathbf{2 2}$ \\
Excluded & & & & & & & \\
Technically poor & 11 & 5 & 4 & 2 & 0 & 0 & 0 \\
Conduction disorder & 7 & 3 & 0 & 0 & 0 & 0 & 0 \\
Short recovery & 11 & 16 & 4 & 2 & 3 & 4 & 0 \\
Arrhythmia & 4 & 2 & 1 & 0 & 2 & 0 & 0 \\
Pacemaker & 1 & 2 & 2 & 1 & 1 & 1 & 1 \\
IHD before current test & 3 & 2 & 4 & 3 & 2 & 2 & 0 \\
LVH with ST deviation & 1 & 1 & 0 & 0 & 0 & 0 & 0 \\
Other & 3 & 3 & 0 & 0 & 0 & 0 & 0 \\
\hline Excluded tests (\%) & 0.1 & 0.1 & 0.1 & 0.1 & 0.1 & 0.2 & 0.0 \\
\hline
\end{tabular}

$I H D=$ ischaemic heart disease, $L V H=$ left ventricular hypertrophy 


\section{Calculations}

Exercise electrocardiography (ExECG)

The following ExECG variables were calculated for each lead:

- ST depression

Negative ST deflection at peak exercise. If present, any baseline (resting) negative ST deviation was subtracted. A peak exercise ST depression of $\geq 0.1 \mathrm{mV}$ was considered significant and was called ST $\mathrm{ST}_{\text {dep }}$.

Comment: In the papers included in this dissertation, a significant ST depression has been referred to as both "ST $\mathrm{Sep}_{\text {dep }} \leq-\mathrm{O} .1 \mathrm{mV}$ " (paper III) and "ST ${ }_{\text {dep }} \geq 0.1 \mathrm{mV}$ " (papers II and IV), although they refer to the same electrocardiographic changes. Consistent terminology was used within each paper.

- $\mathrm{ST} / \mathrm{HR}$ index

The change in ST level from rest to peak exercise divided by the HR increase during the same period (Fig. 2).

- ST/HR slope

The slope at the end of the ST/HR plot was evaluated beginning with linear regression analysis of the four rightmost ST/HR pairs and successively adding more data points until significance of the regression line was reached. If there was no significant linear fit when reaching the lowest HR, no ST/HR slope value was accepted for that lead (Fig. 2).

- ST/HR loop characteristics

By splitting the ST/HR loop into two halves and comparing the ST/HR data points from the work and rest phases in the respective halves, we characterised the ST/HR loop as rotating clockwise, rotating counterclockwise, crossed, or flat (Fig. 5).

- Normalised area (NA) of the ST/HR loop

The area covering the upper $70 \%$ of the HR increase was calculated and divided by the included HR span. 
Counterclockwise

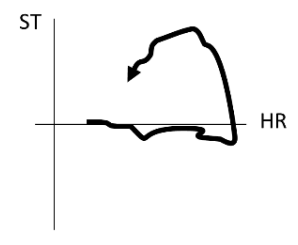

Clockwise

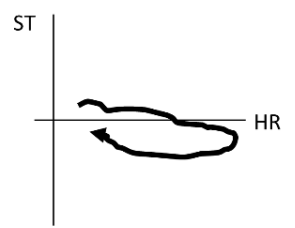

Counterclockwise crossing

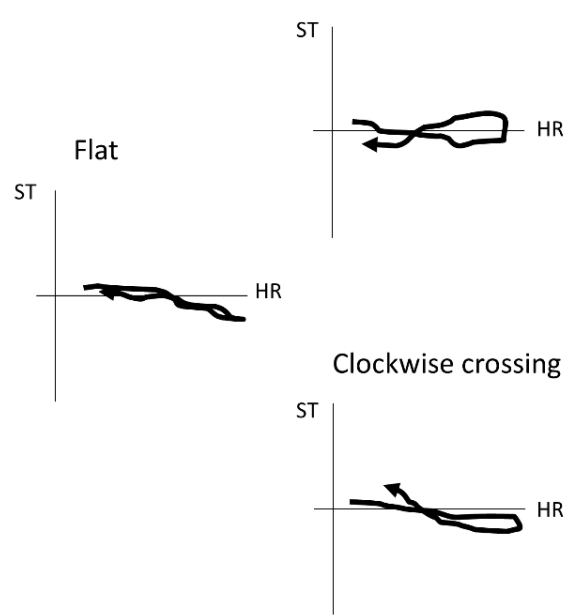

Figure 5. Typical ST/HR loop patterns.

$H R=$ heart rate

Cycle ergometer (CE) tests

For estimation of $\mathrm{VO}_{2}$ during $\mathrm{CE}$, we used the following prediction equation from the American College of Sports Medicine (ACSM) [53].

$$
\mathrm{VO}_{2}(\mathrm{ml} / \mathrm{min})=(1.8 * 6.12 \mathrm{P})+\mathrm{M}_{\mathrm{b}}(3.5+3.5)
$$

$$
\mathrm{VO}_{2}(\mathrm{ml} / \mathrm{kg} / \mathrm{min})=\left(1.8 * 6.12 \mathrm{P} / \mathrm{M}_{\mathrm{b}}\right)+3.5+3.5
$$

in which $\mathrm{P}=$ power output $(\mathrm{W})$ and $\mathrm{M}_{\mathrm{b}}=$ body mass of the test subject (kg).

To compare performance in the incremental ramp CE test with the CWL cycling test, the $\mathrm{P}_{\max }$ from the ramp cycling test was converted to the maximal CWL that the individual was expected to maintain for $6 \min \left(\mathrm{P}_{\max 6}\right)$ using the following equation [54]:

$$
\mathrm{P}_{\max 6^{\prime}}=\left[\left(\mathrm{P}_{\mathrm{a}, \mathrm{b}}\right)^{6} /(36 \mathrm{~b})\right]^{\mathrm{o}, 2}
$$


in which $\mathrm{P}_{\mathrm{a}, \mathrm{b}}=$ the final workload, $\mathrm{a}=$ the initial workload, and $\mathrm{b}=$ the increase in workload per minute.

Accordingly, a $\mathrm{P}_{\max }$ of $250 \mathrm{~W}$ corresponds to a $\mathrm{P}_{\max }$ of $\sim 200 \mathrm{~W}$. A $P_{\max } \geq 250 \mathrm{~W}$ during the incremental ramp test was considered equivalent to passing the $6 \mathrm{~min}$ CWL test at $200 \mathrm{~W}$.

\section{Treadmill (TM) tests}

To calculate the gross metabolic rate during gradient walking with added weight, the Pandolf prediction equation [55] was used:

$$
\mathrm{P}(\mathrm{W})=1.5 \mathrm{M}_{\mathrm{b}}+2\left(\mathrm{M}_{\mathrm{b}}+\mathrm{M}_{\mathrm{l}}\right)\left(\mathrm{M}_{\mathrm{l}} / \mathrm{M}_{\mathrm{b}}\right)^{2}+\mathrm{y}\left(\mathrm{M}_{\mathrm{b}}+\mathrm{M}_{\mathrm{l}}\right)\left[1.5 \mathrm{~V}^{2}+0.35 \mathrm{VG}\right]
$$

in which $\mathrm{M}_{\mathrm{b}}=$ body mass $(\mathrm{kg}), \mathrm{M}_{\mathrm{l}}=$ the weight of the load $(\mathrm{kg}), \mathrm{y}=$ terrain factor $(\mathrm{y}=1$ for $\mathrm{TM}), \mathrm{V}=$ speed $(\mathrm{m} / \mathrm{s})$ and $\mathrm{G}=$ inclination (grade).

By using indirect calorimetry, the calculated gross energy expenditure was converted to gross oxygen expenditure by assuming that $1 \mathrm{ml}$ of oxygen produces $20.1 \mathrm{~J}$ of energy for work performed in submaximal, aerobic conditions [56]. 


\section{Concepts of test interpretation}

The interpretation of a test result must be done in the context in which the test was performed and with respect to the predefined question of interest. A useful diagnostic test adds valuable information to increase the probability that a patient will be correctly classified as diseased or not diseased, compared to what was known before performing the test, thus aids the clinician in the care of the patient.

\section{Sensitivity and specificity}

Sensitivity is the proportion of individuals with true positive test results among all of the subjects with the disease, i.e. the ability of the test to correctly identify diseased subjects (the true positive rate). Specificity, on the other hand, is the proportion of individuals with true negative test results among all of the healthy individuals (the true negative rate). Sensitivity and specificity are in-born properties of a test that determine its ability to accurately detect or reject a disease diagnosis (Fig. 6).

In addition, estimation of the sensitivity and specificity of specific parameters depends on accuracy of the reference method. That is, if $10 \%$ of the population stated as healthy actually have the disease, but the "gold standard" method was unable to detect it, the analysed parameter can reach a maximum specificity of $90 \%$.

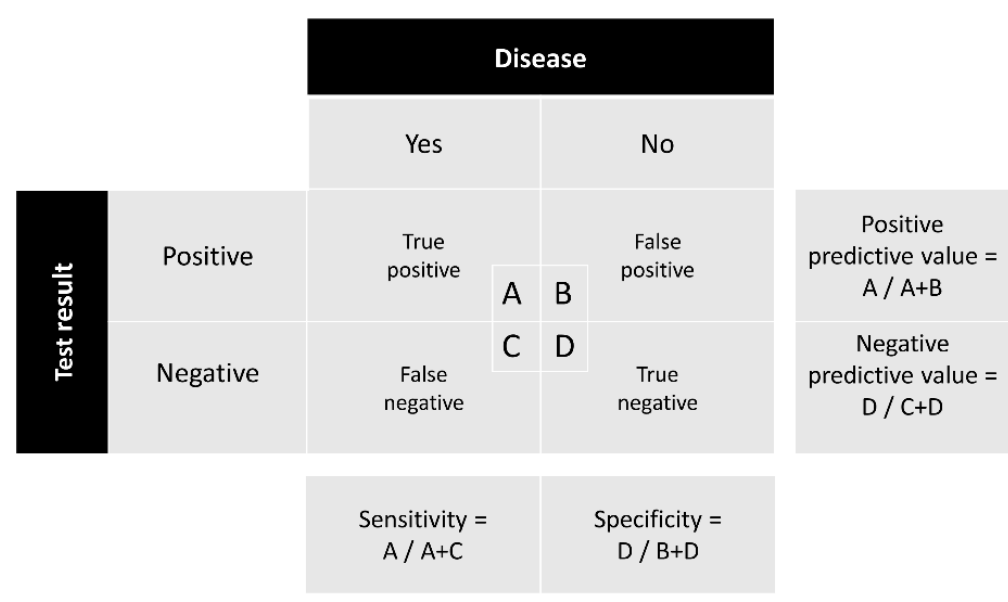

Figure 6. A conventional $2 \times 2$ table representing the relationships between test results and sensitivity, specificity, and positive and negative predictive values. 


\section{Pre-test and post-test probabilities}

In a clinical situation, the pre-test probability is equal to the prevalence of a disease, i.e. the likelihood that a subject in a certain population has a certain disease before performing any diagnostic testing. Accordingly, post-test probability is the probability that a subject has a disease after knowledge has been gained from a diagnostic test result. The pre-test probability has a high impact on the clinical usefulness of a test.

\section{Positive and negative predictive values}

While sensitivity and specificity values are intrinsic to the parameter itself, the clinical usefulness of a test in different populations also depends on the prevalence of the disease in the specific population. This relationship is described by the positive predictive value (PPV). The PPV describes how likely it is that a patient with a positive test result actually has the disease. The PPV is calculated as the number of diseased persons with positive test results divided by the number of all persons with positive test results. A negative predictive value represents the number of true negative test results among all persons with negative test results (Fig. 6). Thus, in populations with low prevalence of the studied disease, the PPV would be expected to be low even if the sensitivity is considerably high. These relationships, also called the conditional probability of disease, are derived from the Bayesian theorem, and hold true for detection of IHD by ExECG in different populations [57]. 


\section{Ethics}

Studies I-IV were conducted according to the principles of the Declaration of Helsinki and were approved by the regional ethic review board (diary number 2011/290-31 and 2017/243-32). Informed consent was obtained from all of the participants included in studies III-IV.

\section{Statistics}

SPSS statistical software (SPSS Statistics v. 21-24, IBM) was used for analyses. P-values <0.05 were considered significant. The independent samples t-test was used to compare mean values and the chi-squared test was used to compare categorical data. Mean values were expressed as mean \pm SD. The paired samples t-test was used to analyse individual performances in different tests. Pearson's correlation was used to determine correlations. Binary logistic regression analyses were performed to identify independent predictors of IHD among ExECG parameters with imaging verified ischaemia as the dependent variable. 


\section{RESULTS}

\section{Exercise capacity}

TM and CE tests of 424 firefighters were retrospectively analysed.

\section{Constant workload (CWL) tests}

Due to changes in the required test procedure used to evaluate the fitness of firefighters [42], the number of $200 \mathrm{~W} \mathrm{CWL} \mathrm{CE} \mathrm{tests} \mathrm{performed} \mathrm{dimin-}$ ished in 2006 and were no longer performed by the end of 2007.

TM tests were available for the study cohort from 2006, thus there were 2 years (2006-2007) when CWL tests of both modalities (TM and CE) were performed (Fig. 7).

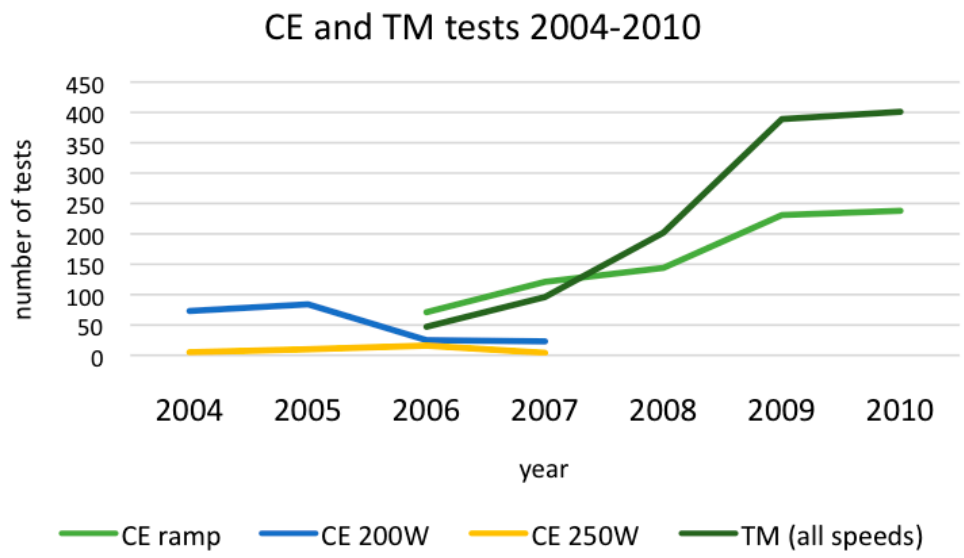

Figure 7. Distribution of test types during the study period for subjects who had performed at least one $\mathrm{CE}$ and one TM test $(\mathrm{n}=424)$. $\mathrm{CE} 200 \mathrm{~W}$ and $\mathrm{CE}$ $250 \mathrm{~W}$ indicate constant workload tests at 200 and $250 \mathrm{~W}$, respectively.

$C E=$ cycle ergometer,$T M=$ treadmill

\section{Observed and calculated parameters}

In total, 97 subjects performed both CE (200 W) and TM $(4.5 \mathrm{~km} / \mathrm{h}) \mathrm{CWL}$ tests during the study period. Only 12 subjects performed both tests within 12 months, which was considered too few for further analyses. Instead, we selected the most recently performed CE (200 W) and TM $(4.5 \mathrm{~km} / \mathrm{h})$ 
test for each of the 97 subjects for analysis (Table 4). The mean time difference between the tests was $3.3 \pm 1.7$ years.

The calculated oxygen uptake (absolute numbers and after adjustment for body weight) was found to be higher in the TM test than in the $\mathrm{CE}$ test. In addition, although the subjects were older (50 vs. 45 years of age) at the time of the TM test, the $\mathrm{HR}_{\text {peak }}$ was higher at the end of the TM test. Thus, the $\mathrm{HR}_{\text {peak }}$ as a percentage of the predicted maximal HR was higher in the TM test (97\%) than in the CE test (90\%).

Table 4. Calculated and measured variables from the two modalities (TM and CE) of constant workload exercise tests. HR variables reflect the end of the work phase and were only analysed for subjects who completed all 6 min of both tests $(\mathrm{n}=88)$.

\begin{tabular}{|c|c|c|c|c|c|c|c|}
\hline & \multirow{2}{*}{\multicolumn{3}{|c|}{ CE $200 \mathrm{~W}$}} & \multirow{2}{*}{\multicolumn{3}{|c|}{ TM 4.5 km/h }} & \multirow[b]{3}{*}{$\mathbf{p}$} \\
\hline & & & & & & & \\
\hline & Mean & SD & Range & Mean & SD & Range & \\
\hline \multicolumn{8}{|c|}{ Calculated $(n=97)$} \\
\hline $\begin{array}{l}\mathrm{VO}_{2}, \\
\mathrm{ml} / \mathrm{kg} / \mathrm{min}\end{array}$ & 33 & 3 & $27-44$ & 38 & 1 & $36-41$ & $<0.001$ \\
\hline $\mathrm{VO}_{2}, \mathrm{~L} / \mathrm{min}$ & 2.8 & 0.1 & $2.6-3.0$ & 3.3 & 0.3 & $2.5-4.0$ & $<0.001$ \\
\hline \multicolumn{8}{|c|}{ Measured $(n=88)$} \\
\hline $\begin{array}{l}\text { HR } R_{\text {peak, }} \\
\text { beats/min }\end{array}$ & 158 & 16 & $122-194$ & 166 & 13 & $132-194$ & $<0.001$ \\
\hline $\begin{array}{l}\mathrm{HR} \% \max , \\
\%\end{array}$ & 90 & 8 & $69-108$ & 97 & 6 & $77-110$ & $<0.001$ \\
\hline \multicolumn{8}{|c|}{ Observed $(n=97)$} \\
\hline Age, years & 45 & 8 & $27-61$ & 50 & 7 & $32-65$ & $<0.001$ \\
\hline
\end{tabular}

$C E=$ cycle ergometer,$T M=$ treadmill, $H R=$ heart rate

Both test protocols consisted of $6 \mathrm{~min}$ at CWL, and it was required that the entire 6 min were completed for approval. For the CE test, 98\% $(\mathrm{n}=95)$ of the subjects completed the $6 \mathrm{~min}$ at $200 \mathrm{~W}$, whereas $93 \%(\mathrm{n}=$ 90) of the subjects completed the $6 \mathrm{~min}$ TM test. This difference was considered significant $(\mathrm{p}<0.05)$, however no adjustment was made for the older age of the subjects at the time of the TM test.

\section{Heart rate response}

The TM testing was done locally at each fire station by designated test leaders. Official requirements for the TM test include predefined settings for the TM and clothing and gear for the firefighter, but do not require any medical monitoring or assessment of physiological parameters. Nevertheless, all of the fire stations in these studies used a pulse watch with a chest strap to monitor HR and typically recorded the HR at the end of 
each minute. During the last $4 \mathrm{~min}$ of the TM test at $4.5 \mathrm{~km} / \mathrm{h}$, the HR increased an average of 11 beats/min (range $0-26$ ).

\section{Incremental workload tests}

The study participants performed an average of $2.4 \pm 1.8 \mathrm{CE}$ ramp tests per person.

\section{Change in working capacity over time}

When we analysed the entire initial study cohort, 667 individuals had performed at least one pure incremental ramp CE test. The mean $\mathrm{P}_{\max }$ of the first CE ramp test was $281 \pm 36 \mathrm{~W}$ (range 186-467 W) and the mean age at the time of the test was $44 \pm 10$ years (range 21-68 years). For reference, the expected maximal exercise capacity of a $180 \mathrm{~cm}$ 44-year-old man in the general Swedish population is $270 \mathrm{~W}$ [58].

For those who had performed at least two CE ramp tests, the mean time between the first and second test was $18 \pm 10$ months (the different inter-test intervals were due to age-dependent regulations [42]) and the average difference in performance was $-1.8 \pm 22 \mathrm{~W}$, which corresponds to an average annual decline of $1.2 \mathrm{~W}$.

Furthermore, subanalysis based on age revealed that in the youngest subgroup aged 20-29 years at inclusion, the average performance increased with time. In the 30-39 and 40-49 years of age subgroups, the average performance remained stable. In the subgroup over 50 years of age, the average performance decreased over time (Fig. 8).

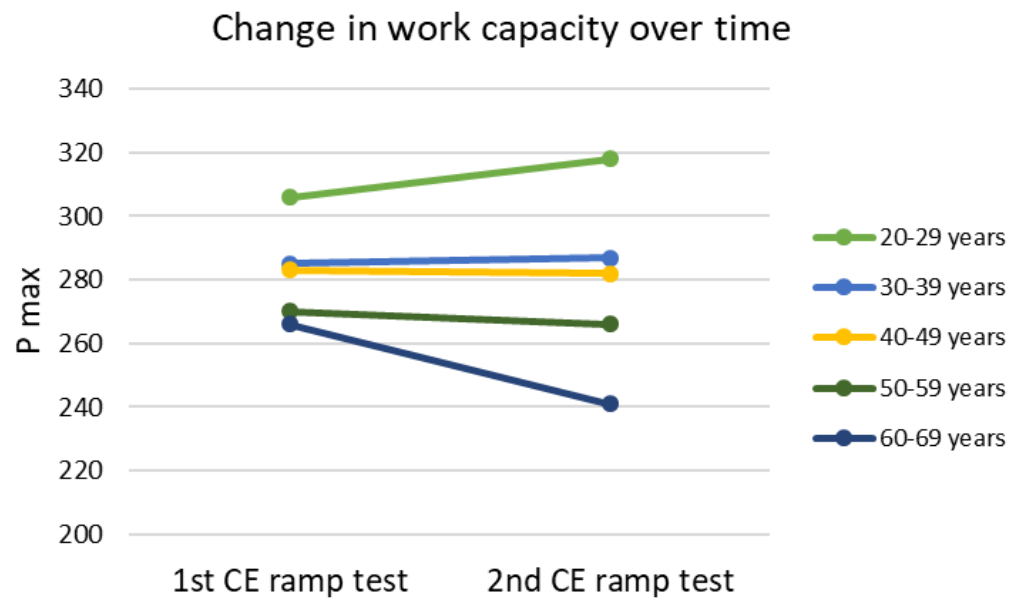

Figure 8a. Maximal workload $\left(\mathrm{P}_{\max }\right.$ ) of the first and second available cycle ergometer (CE) ramp tests, subdivided by age at first test. 


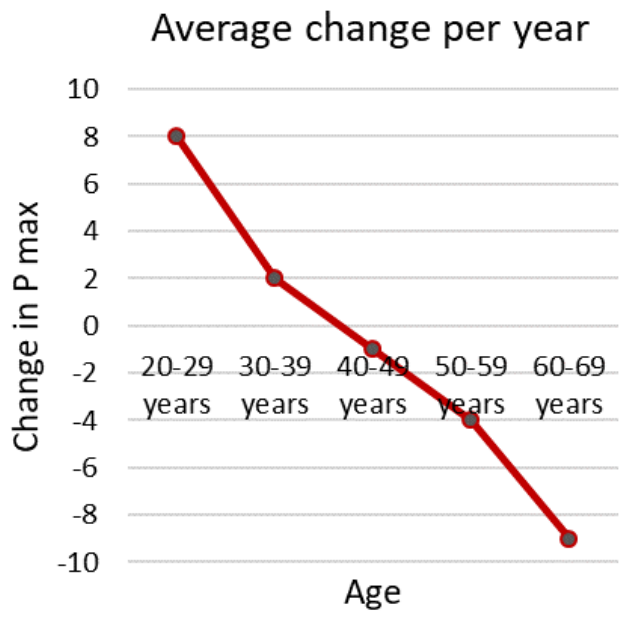

Figure 8b. Change in maximal work capacity $\left(\mathrm{P}_{\max }\right)$ over time, as average change in $\mathrm{P}_{\max }$ per year, subdivided by age at first test.

\section{Comparing cycle ergometer and treadmill performance}

We matched the TM test at $4.5 \mathrm{~km} / \mathrm{h}$ with the CE ramp test performed by the same subject within 12 months and compared the accomplishments. Test approval was defined as completing $6 \mathrm{~min}$ on the TM and achieving a $\mathrm{P}_{\max } \geq 250 \mathrm{~W}$ in the $\mathrm{CE}$ ramp test.

In total, there were 221 individuals who had available data for comparison and 168 of them (76\%) passed both tests. Fourty-four firefighters (20\%) passed the TM test but not the CE test, while the opposite was the case for only one firefighter (0.5\%), p<0.001. Eight subjects $(3.5 \%)$ did not pass either of the tests.

Subjects that failed both tests were significantly shorter, older, and had a higher body mass index (BMI) than the subjects who passed both tests. Subjects who passed the TM test but failed the CE test had a lower BMI and a lower body surface area than those who passed both tests, thus being lighter and shorter.

\section{Effect of body composition on test performance}

Predictors of the ability to perform a CE ramp test with a $\mathrm{P}_{\max }$ higher than or equivalent to $6 \mathrm{~min}$ of CWL at $200 \mathrm{~W}$ were young age, tall stature, and full-time employment. Age, height, and BMI also associated with the ability to complete $6 \mathrm{~min}$ of the TM test at $4.5 \mathrm{~km} / \mathrm{h} \mathrm{TM}$, as well as did lower body weight (Table 5). 


\section{Methodological consideration}

To allow for comparison between the CE and the TM tests, we converted the incremental ramp CE test to the corresponding workload that an individual was expected to maintain for $6 \min \left(\mathrm{P}_{\max } 6^{\prime}\right)$ using a previously published method (see the Methods section for the equation).

Among the entire cohort, no individual performed both the incremental ramp and CWL CE tests during the same calendar year. However, from 2005-2007, both the incremental ramp and CWL CE tests were available for 74 of the firefighters with up to 2 years between the tests. To assess the methodologies based on the available tests, we converted the CE incremental ramp $\mathrm{P}_{\max }$ to $\mathrm{P}_{\max } 6$ ' and compared this value with the $200 \mathrm{~W}$ CWL test. Two individuals failed to complete the $6 \mathrm{~min}$ at $200 \mathrm{~W}$. Their corresponding $\mathrm{P}_{\max } 6$ ' values from the ramp test were $142 \mathrm{~W}$ and $202 \mathrm{~W}$. Of the remaining 72 subjects in this analysis who completed the 6 min $200 \mathrm{~W}$ CWL test, $85 \%$ reached $\mathrm{P}_{\max } 6$ ' values $>200 \mathrm{~W}$ (mean $231 \mathrm{~W}$, range 202$323 \mathrm{~W}$ ) while $15 \%$ reached $\mathrm{P}_{\max } 6$ ' values $<200 \mathrm{~W}$ (mean $187 \mathrm{~W}$, range $176-$ $197 \mathrm{~W})$.

Table 5. Factors associated with the ability to complete a CE ramp test equivalent to $6 \mathrm{~min}$ at $200 \mathrm{~W}$ (Pmax6' $\geq 200 \mathrm{~W}$ ) and the ability to complete a 6 min $\mathrm{TM}$ test at $4.5 \mathrm{~km} / \mathrm{h}$. For the equation used to convert the CE ramp test to CWL, see the Methods section.

\begin{tabular}{ccccc} 
& \multicolumn{2}{c}{$\begin{array}{c}\text { CE } \mathbf{P}_{\max } \mathbf{6}^{\prime} \geq 200 \mathbf{~ W} \\
(\mathrm{n}=384)\end{array}$} & \multicolumn{2}{c}{ TM 6 min 4.5 km/h } \\
$(\mathrm{n}=259)$ & \\
\hline & OR (95\% Cl) & $\mathbf{p}$ & OR (95\% Cl) & $\mathbf{P}$ \\
\hline Age (years) & $0.92(0.89-0.95)$ & $<0.001$ & $0.89(0.81-0.98)$ & 0.013 \\
Height (cm) & $1.09(1.03-1.16)$ & 0.005 & $1.13(1.01-1.25)$ & 0.031 \\
Body mass $(\mathrm{kg})$ & $1.01(0.98-1.05)$ & 0.461 & $0.92(0.87-0.98)$ & 0.006 \\
Employment & $3.65(1.83-7.29)$ & $<0.001$ & $2.23(0.43-11.48)$ & 0.338 \\
Gender & $0.27(0.06-1.35)$ & 0.112 & - & - \\
\hline
\end{tabular}

Employment was defined as part-time workers $=1$ and full-time workers $=2$. Gender was defined as male $=1$ and female $=2$. The effect of gender was not calculated for TM because too few females were available for analysis. 


\section{Acquisition and processing of ExECG data}

The ExECG test results were originally stored in a large clinical database from which tests performed by study subjects were manually exported to a research database file. The ExECG software used for clinical testing and analysis reported the main variables of interest for each individual test. However, the data were not instantly accessible for extended calculations and analyses and had to be systematically extracted and processed.

Using structured query language (SQL), a short script was written to retrieve, copy, and sort specific ExECG data from each individual test in the database. At this step, data were checked for inconsistencies, such as unintentional exchange of height and weight values. Then, an analysis

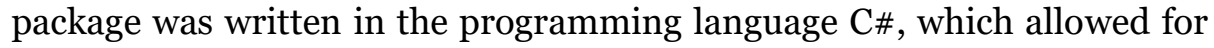
data validation, error checking, and calculation of ST/HR parameters. Finally, all data were imported to the statistical program SPSS for statistical analyses.

\section{Transition from work to rest}

Most of the ExECG parameters analysed in paper III depend on accurate identification of the transition time from the work phase to the rest phase. Due to a number of practical issues inherent in manual recordings, the precise recording of the transition time may be subject to errors, normally delays, which would confound identification of the ST/HR loop as well as determination of the ST/HR index, ST/HR slope, ST level at peak work rate, and maximum work capacity.

Therefore, we repeatedly checked the HR/time curve for a steep change in the HR/time slope. The point of change from a positive or near zero slope to a negative slope was considered the most accurate time for the "end-of-work".

In $96 \%$ of the tests analysed in paper III, the adjusted end-of-work coincided with the manually registered timepoint. In $2 \%$ of the tests, the adjusted end-of-work occurred within $15 \mathrm{~s}$ before the manual recording, and in the remaining $2 \%$ of the tests, the adjustment was an average of $34 \mathrm{~s}$ (range 16-73 s).

\section{Noise detection and filtering}

To reduce noise, both ST60 and HR data were filtered with a three-point moving median.

Noise in the ST and HR data was also assessed with a noise index, which was calculated by summing the differences between neighbouring data in each recording and dividing this sum by the number of data points 
included. Leads with abnormal noise indices, which were identified by visualisation in a histogram, were manually checked. By checking noise indices, leads/recordings with arrhythmias, loose electrodes, and extensive muscular disturbances were identified. Often, erroneous ST registrations were restricted to a limited number of leads that could be excluded if found inappropriate, whereas inaccurate HR recordings that were not smoothed by median filtering could cause an entire test to be excluded.

The average ST noise index for all of the ECG leads from the first available test for each subject were 0.24-0.35 $\mu \mathrm{V}$ ( $\pm 0.22-0.43)$ with maximum values between 2.5 and 10.7 for the different leads. After test selection and quality assessment, the mean ST noise index for the tests included in paper III were 0.20-0.28 V ( \pm SD 0.11-0.16). 


\section{Identification of IHD}

\section{Ischaemic heart disease (IHD)}

ExECG data for 521 male firefighters were evaluated with a special focus on the ST and ST/HR variables. During $8.4 \pm 2.1$ years of follow-up, 12 subjects were identified with IHD (Table 6) and were compared to the 509 subjects who had either negative $(\mathrm{n}=35)$, inconclusive/nonsignificant findings $(n=8)$, or no available imaging studies $(n=466)$ for IHD during the entire follow-up (paper III).

Table 6. Males diagnosed with IHD during the follow-up. All of the subjects with pathological findings by computed tomography were also examined by coronary angiography, and all were found to have significant coronary artery luminal reduction.

\begin{tabular}{|c|c|c|c|c|c|c|c|}
\hline \multirow[b]{2}{*}{$\begin{array}{c}\text { Age at } \\
\text { diag- } \\
\text { nosis } \\
\text { (years) }\end{array}$} & \multirow[b]{2}{*}{$\begin{array}{l}\text { Time from } \\
\text { test to di- } \\
\text { agnosis } \\
\text { (years) }\end{array}$} & \multirow[b]{2}{*}{$\begin{array}{l}\text { IHD first } \\
\text { identi- } \\
\text { fied by }\end{array}$} & \multicolumn{5}{|c|}{ Number of leads with } \\
\hline & & & $\begin{array}{c}\text { Clockwise } \\
\text { rotating } \\
\text { ST/HR } \\
\text { loops }\end{array}$ & $\begin{array}{l}\text { STdep } \\
\text { (downward } \\
\text { sloping) }\end{array}$ & $\begin{array}{c}\mathrm{ST} / \mathrm{HR} \\
\text { index } \leq \\
-1.6 \\
\mu \mathrm{d} / \text { beats } \\
\text { /min }\end{array}$ & $\begin{array}{c}\text { ST/HR } \\
\text { slope } \leq \\
-2.4 \\
\mu \mathrm{V} / \text { beat } \\
\text { s/min }\end{array}$ & $\begin{array}{c}\text { Nega- } \\
\text { tive NA }\end{array}$ \\
\hline 62 & 3.1 & $\mathrm{CA}$ & 0 & 0 & 0 & 0 & 0 \\
\hline 63 & 5.8 & $\mathrm{CA}$ & 0 & $5(0)$ & 2 & 4 & 1 \\
\hline 54 & 1.1 & $\mathrm{CA}$ & 2 & 0 & 0 & 3 & 9 \\
\hline 54 & 0.3 & $\mathrm{CA}$ & 0 & 0 & 0 & 0 & 0 \\
\hline 55 & 2.5 & $\mathrm{CA}$ & 0 & 0 & 0 & 3 & 0 \\
\hline 57 & 0.3 & MPI & 9 & $7(4)$ & 8 & 8 & 9 \\
\hline 50 & 0.8 & $\mathrm{CA}$ & 1 & 0 & 0 & 0 & 2 \\
\hline 53 & 1.4 & ССТА & 0 & 0 & 0 & 0 & 0 \\
\hline 51 & 5.9 & $\mathrm{CA}$ & 0 & 0 & 0 & 0 & 1 \\
\hline 56 & 3.0 & ССТА & 0 & 0 & 0 & 0 & 0 \\
\hline 47 & 4.8 & $\mathrm{CA}$ & 0 & $3(2)$ & 3 & 6 & 0 \\
\hline 48 & 0.1 & ССТА & 0 & $3(0)$ & 2 & 6 & 0 \\
\hline
\end{tabular}

$C A=$ coronary angiography, $C C T A=$ coronary computed tomography angiography, $I H D=$ ischaemic heart disease, $M P I=$ myocardial perfusion imaging, $S T_{\text {dep }}=\geq 0.1 \mathrm{mVST}$ depression, $N A=$ normalised area 


\section{ST depression}

A significant exercise-induced ST depression $\left(\mathrm{ST}_{\text {dep }}\right)$ was defined as an additional negative ST deflection of $\geq 0.1 \mathrm{mV}$ at peak exercise compared to baseline. $\mathrm{ST}_{\text {dep }}$ was found in $20 \%$ of the population (paper III), and among them, $76 \%$ developed ST depression in two or more leads (Fig. 9). $\mathrm{ST}_{\text {dep }}$ was most common in the III, V5, and V6 leads with a frequency of $>10 \%$. In the precordial leads, the $\mathrm{ST}_{\text {dep }}$ was most commonly observed sloping upwards, whereas a downward sloping ST segment was more frequently observed in the extremity leads (Fig. 10).

However, a significant association between $\mathrm{ST}_{\text {dep }}$ and IHD was only found in lead V4 (Table 7). In a receiver operating characteristic (ROC) curve that allowed for visualisation of the $\mathrm{ST}_{\max }$ to distinguish IHD from non-IHD, the area under the curve was 73\% (Fig. 11). For the ROC curve analysis, $\mathrm{ST}_{\max }$ was used instead of $\mathrm{ST}_{\text {dep }}$ so that all of subjects were included regardless of the ST level at maximum work.

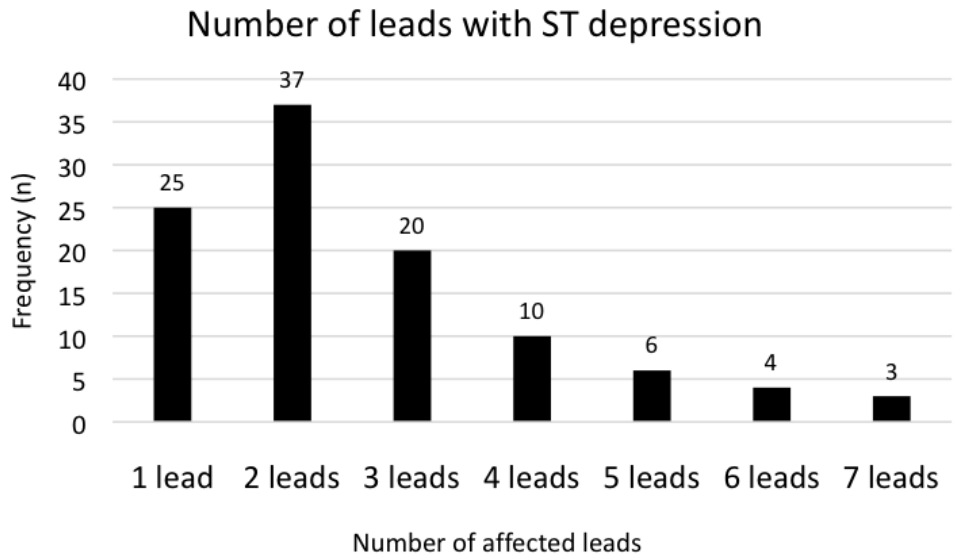

Figure 9. Number of leads with an ST depression $\geq 0.1 \mathrm{mV}$ based on a subgroup of firefighters who presented with ST depression in at least one lead ( $\mathrm{n}=$ 105).

Table 7. Association between ST depression $\geq 0.1 \mathrm{mV}$ and IHD in the different leads, adjusted for age. Leads with $\leq 2$ positive cases were not analysed (-).

\begin{tabular}{ccccccccccc}
\hline & I & -aVR & II & aVF & III & V2 & V3 & V4 & V5 & V6 \\
\hline OR & - & 4.1 & 2.3 & 2.1 & 1.6 & - & - & $9.6^{* *}$ & 3.0 & 2.6 \\
CI & - & $0.5-$ & $0.5-$ & $0.4-$ & $0.3-$ & - & - & $2.3-$ & $0.8-$ & $0.7-$ \\
& & 37.2 & 11.0 & 10.3 & 7.5 & & & 40.0 & 10.9 & 9.3 \\
\hline
\end{tabular}

$C I=$ confidence interval 


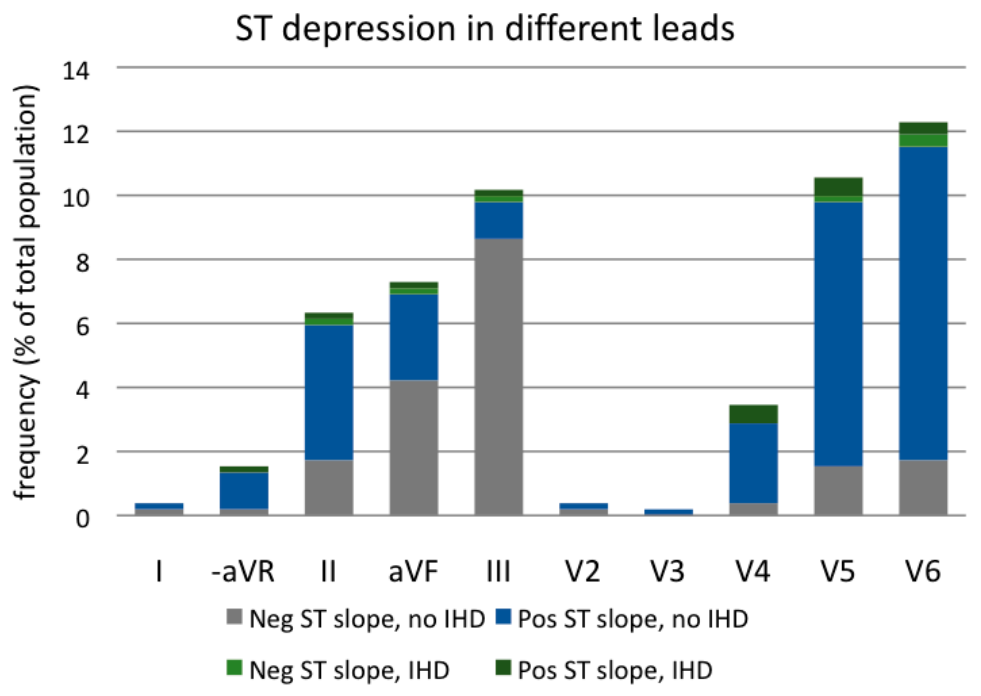

Figure 10. Frequency of ST depressions $\geq 0.1 \mathrm{mV}$ at the end of exercise in the different leads.

$I H D=$ ischaemic heart disease

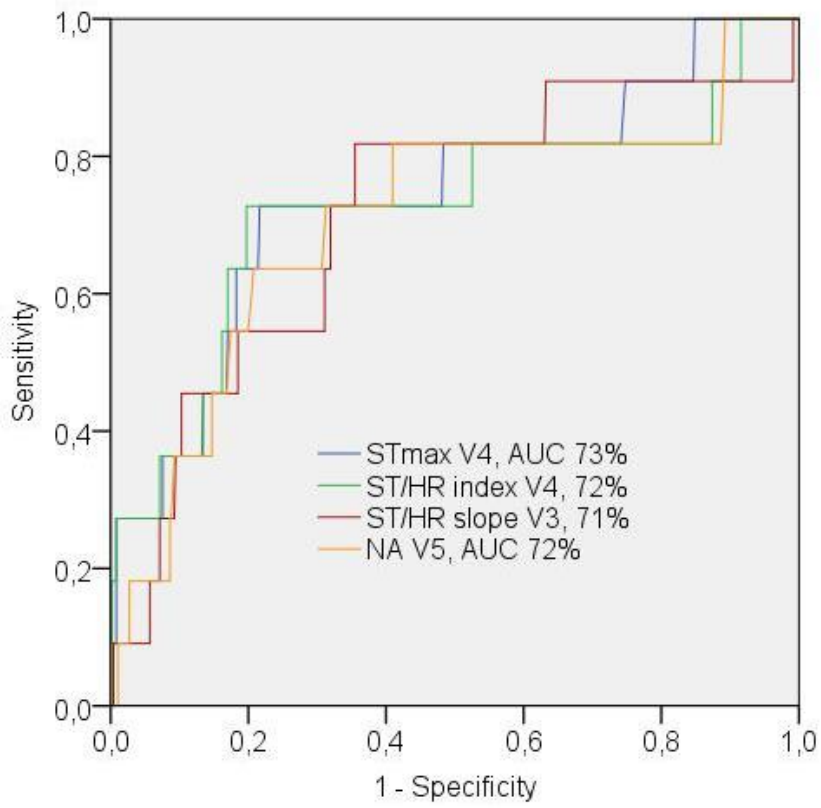

Figure 11. Reciever operating characteristic curves of risk for IHD based on the ST $_{\max }$, ST/HR slope, ST/HR index, and normalised areas (NAs). The best performing lead was selected for each variable.

$A U C=$ area under the curve, $C I=$ confidence interval 


\section{$S T / H R$ index and $S T / H R$ slope}

For all of the leads where the ST level at maximum work was negative, the ST/HR index and ST/HR slope were calculated. An ST/HR index $\leq-1.6$ $\mu \mathrm{V} / \mathrm{bpm}$ and a ST/HR slope $\leq-2.4 \mu \mathrm{V} / \mathrm{bpm}$ were considered suggestive of ischaemia as previously proposed [24]. In our population, ST/HR index and ST/HR slope values below those cut-offs in lead V4 associated with an increased risk for IHD, whereas most of the other leads did not show this association (Table 8).

Table 8. a) Association between an ST/HR index $\leq-1.6 \mu \mathrm{V} / \mathrm{bpm}$ and IHD in different leads. b) Association between a ST/HR slope $\leq-2.4 \mu \mathrm{V} / \mathrm{bpm}$ and IHD in different leads. The calculations were adjusted for age. These associations were not evaluated for leads with $\leq 2$ positive cases (-).

8a.

\begin{tabular}{ccccccccccc}
\hline & I & -aVR & II & aVF & III & V2 & V3 & V4 & V5 & V6 \\
\hline OR & - & $18.7^{*}$ & 5.0 & 2.4 & 1.9 & - & - & $27.5^{* * *}$ & $4.3^{*}$ & 4.0 \\
CI & - & $1.6-$ & $1.0-$ & $0.3-$ & $0.2-$ & - & - & $5.6-$ & $1.0-$ & $1.0-$ \\
& & 224.1 & 25.7 & 20.1 & 15.2 & & & 134.5 & 17.4 & 16.7 \\
\hline
\end{tabular}

8b.

\begin{tabular}{ccccccccccc}
\hline & I & -aVR & II & aVF & III & V2 & V3 & V4 & V5 & V6 \\
\hline OR & 0 & 2.7 & $5.7^{* *}$ & $3.9^{*}$ & 2.7 & 0 & 6.9 & $5.1^{*}$ & 2.7 & 2.5 \\
CI & $0.0-$ & $0.6-$ & $1.7-$ & $1.1-$ & $0.7-$ & $0.0-$ & $0.7-$ & $1.4-$ & $0.8-$ & $0.7-$ \\
& & 13.1 & 19.2 & 13.5 & 8.9 & 0.7 & 68.8 & 18.4 & 9.3 & 8.5 \\
\hline
\end{tabular}

$O R=$ odds ratio, $C I=$ confidence interval

${ }^{*} p<0.05,{ }^{* *} p<0.01,{ }^{* * *} p<0.001$

\section{The ST/HR loop}

For all of the leads, ST and HR pairs were plotted during exercise and during the first $3 \mathrm{~min}$ of recovery to create ST/HR loops. The ST/HR loops were categorised into five predefined patterns (Fig. 5). The majority of the ST/HR loops rotated "counterclockwise", i.e. with a recovery ST level more positive than at the same HR during the work phase. This type of loop was used as a normal reference. An inverse loop with a "clockwise" rotation was uncommon in precordial leads (1\%), but associated significantly with IHD. Extremity leads I, -aVR, and II also associated with IHD. Loops starting in either direction but then crossing themselves were analysed separately. While "clockwise-crossing" loops did not associate with IHD in any of the leads, a "counterclockwise-crossing" pattern associated with IHD in the inferior leads (II, aVF, and III). Lastly, loops with little distance between the exercise and recovery ST levels and an unidentifia- 
ble rotation were classified as "flat". In $\mathrm{V}_{5}$, a flat ST/HR loop was indicative of IHD.

The area of the ST/HR loop was calculated for the upper $70 \%$ of the HR span and was normalised for HR by dividing the area by the HR span [49]. There are no established reference values for the NA. We suggested the lowest $5^{\text {th }}$ percentile among non-IHD subjects as a cut-off so that $95 \%$ of all healthy subjects had NAs above the cut-off (Fig. 12). For all of the leads, the partition values were spread closely around zero (Table 9). Subjects with NAs below the lead-specific cut-off in the -aVR, II, aVF, V4, and V5 leads had an increased risk for IHD (Table 9). Three additional ROC analyses of NAs in which each patient was represented by the lead with the most negative NA, the lowest precordial NA, or the lowest extremity NA produced area under the curve (AUC) values of $0.65,0.66$, and $0.66(\mathrm{p}>0.05)$, respectively.

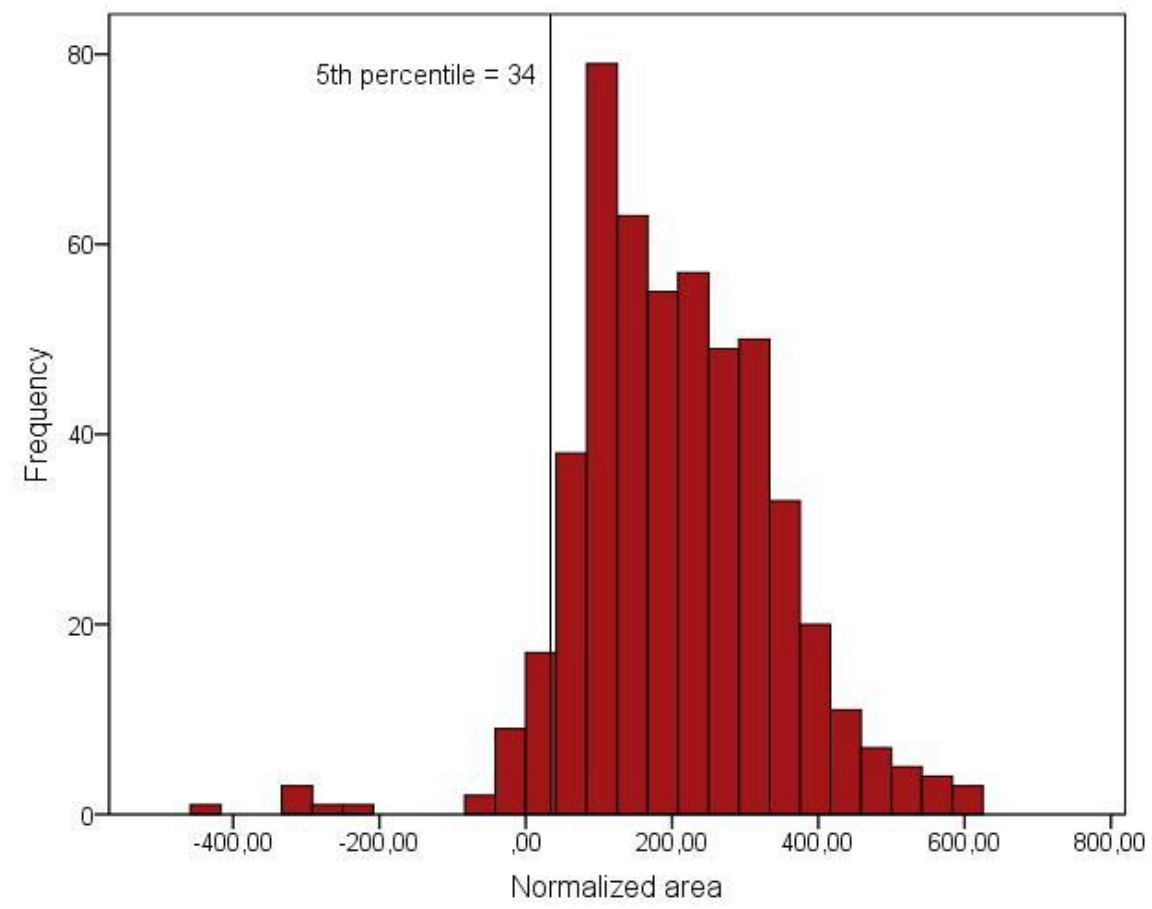

Figure 12. Histogram of the NAs of the ST/HR loops, which were calculated for all of the subjects who did not present objective signs of IHD during followup $(n=509)$. This histogram allows for visualisation of lead V4. The vertical line at 34 is set at the lower 5 th percentile. 
Table 9. Association between the NA of the ST/HR loop and risk for IHD in different leads. Lead-specific cut-offs were based on the lower 5 th percentile of healthy individuals in the cohort. Calculations were adjusted for age.

\begin{tabular}{ccccccccccc} 
& I & - aVR & II & aVF & III & V2 & V3 & V4 & V5 & V6 \\
\hline $\begin{array}{c}\text { Cut-off } \\
(\mu \mathrm{V})\end{array}$ & -6 & -7 & 10 & 1 & -18 & 10 & 20 & 34 & 22 & 16 \\
\hline OR & 4.5 & $6.0^{*}$ & $8.5^{* *}$ & $6.3^{*}$ & 2.1 & 1.3 & 3.3 & $5.2^{*}$ & $5.3^{*}$ & 3.5 \\
& $0.9-$ & $1.5-$ & $2.3-$ & $1.6-$ & $0.3-$ & $0.2-$ & $0.7-$ & $1.3-$ & $1.3-$ & $0.7-$ \\
Cl & 22.3 & 24.2 & 31.1 & 25.4 & 17.5 & 10.9 & 16.2 & 21.5 & 21.9 & 17.4 \\
\hline
\end{tabular}

$O R=$ odds ratio, $C I=$ confidence interval

${ }^{*} p<0.05,{ }^{* *} p<0.01$

Exercise capacity

The relationship between exercise capacity and IHD was analysed for those who had performed the pure incremental ramp CE test. Although the majority of analysed tests were incremental ramp CE tests, $42 \%$ of the IHD subgroup (5/12) had only performed CWL tests and therefore were excluded. The analysis of 406 non-IHD and 7 IHD subjects showed no increased risk of IHD with lower exercise capacity (age-adjusted OR 0.99, CI 0.96-1.01). 


\section{Abnormal ExECG in the absence of IHD}

After exclusion of subjects with verified IHD during follow-up, we studied the relationships between ST depression, test-related variables, and risk factor co-morbidity. This analysis used the most recent ExECG in the study database (paper IV).

\section{ST depression}

By the end of exercise, $22 \%$ of subjects in the non-IHD group developed $\mathrm{ST}_{\text {dep }}$ in at least one lead, mostly in inferolateral leads, and downsloping ST depressions were most common in the inferior leads. Ten percent of subjects had downsloping exercise-induced $\mathrm{ST}_{\text {dep }}$ in at least one lead.

\section{ST depression and age}

Subjects who developed $\mathrm{ST}_{\text {dep }}$ in any of the leads were older than those who did not ( $49 \pm 9$ vs. $45 \pm 11, \mathrm{p}<0.001$ ), and subjects who developed $\mathrm{ST}_{\text {dep }}$ in one or two consecutive precordial leads were also older (both $\mathrm{p}<0.001$ ). Subjects with a downsloping $\mathrm{ST}_{\text {dep }}$ in a precordial or an extremity lead also tended to be older, although the differences were not statistically significant.

\section{ST depression and physiological test response}

There was a positive association between age-adjusted peak exercise HR and $\mathrm{ST}_{\text {dep }}$ (Fig. 13). Similarly, a great HR increase associated with onelead and a two-lead $\mathrm{ST}_{\text {dep }}$ in precordial leads as well as one extremity lead $\mathrm{ST}_{\text {dep }}$ after adjustment for age.

\section{ST depression and cardiovascular risk factors}

Review of the medical records in the subpopulation with no evidence of $\mathrm{CAD}$ at follow-up, revealed that $7 \%$ had either a cardiovascular diagnosis of some kind (category 'I' within the WHO International Classification of Diseases, ICD [48]), hyperlipidaemia, or diabetes registered in their file prior to the examined tests. Within the entire non-CAD study population, $2 \%$ were diagnosed with hypertension, $1 \%$ were diagnosed with diabetes mellitus, and $1 \%$ were diagnosed with hyperlipidaemia. None of these diagnoses, separate or in combination, associated with an increased risk for exercise-induced $\mathrm{ST}_{\text {dep }}$ (Fig. 14). 


\section{3a.}

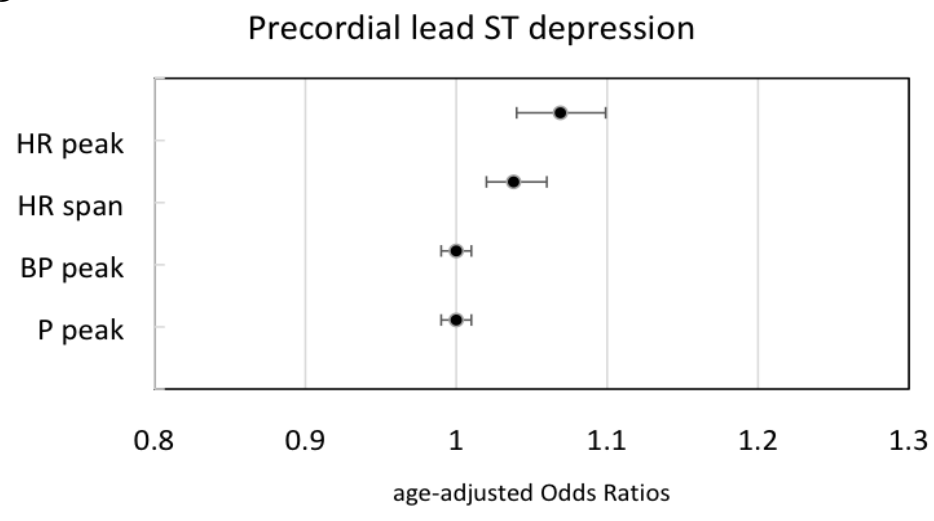

13b.

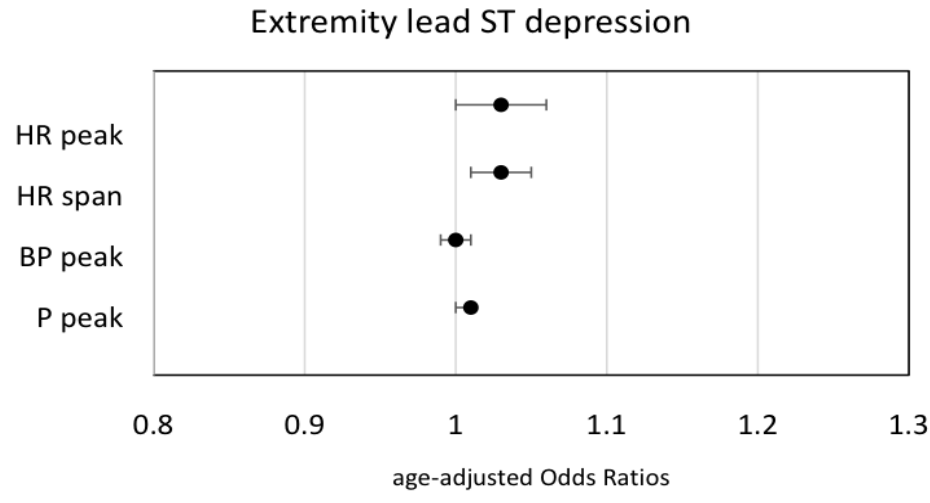

Figure 13. Association between different test performance characteristics and ST depression in a) at least one precordial lead and b) at least one extremity lead.

$H R=$ heart rate, $B P=$ blood pressure, $P=$ power output

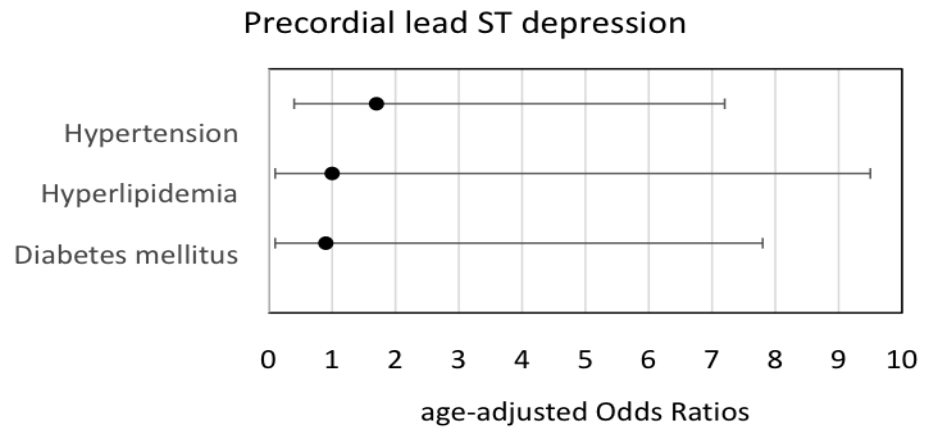

Figure 14. Association between cardiovascular risk factors and ST depression in at least one precordial lead. 
Exercise testing in firefighters

56 


\section{DISCUSSION}

\section{Evaluation of exercise capacity}

Because firefighters require a certain physical capacity to perform firefighting duties in a safe and efficient way, evaluation of the exercise capacity of firefighters is of great importance. It is also crucial that the method for exercise testing is relevant for its purpose.

\section{Different exercise test modalities}

We evaluated 6 min CE and TM CWL tests and incremental ramp CE tests performed by a cohort of firefighters. To enable comparison, the incremental ramp CE test was mathematically converted to the maximal CE workload sustainable for $6 \mathrm{~min}$. It was more common that an individual achieved approval for the newer work-related TM test, but failed to reach the calculated equivalent workload of $250 \mathrm{~W}$ in the CE test during the same year rather than vice versa. Our finding indicates that the TM test was relatively less demanding than the $\mathrm{CE}$ test.

There are several possible factors that contribute to the better TM performance. Walking and carrying heavy firefighter gear is part of the daily routine for this particular study population. Cycling, on the other hand, is not compulsory for firefighters and the quadriceps muscles can become fatigued in subjects unaccustomed to cycling, which may cause premature test termination before reaching the true maximal exercise capacity. Also, after changing the testing procedure in 2008, approval of the TM test is compulsory for continued smoke diving duty, whereas the aim of the CE test is 'only' cardiovascular evaluation. Thus, the firefighters may have put more effort into their TM performance for socioeconomical reasons related to employment even though instructions were given to perform the CE test until exhaustion. High HR values and continued HR drift during the last minutes of TM walking in some of the test subjects indicated that steady state was never established and that exertion may have reached beyond the anaerobic threshold in a near-maximal effort for some of the subjects.

Factors that predicted approval for both the TM test and the CE test were taller height and younger age. Age and height are known to be independent predictors of maximal workload $\left(\mathrm{P}_{\max }\right)$ at ergometer cycling, as well as is gender $[58,59]$. In our analysis, where we assessed the ability to reach $\geq 250 \mathrm{~W}$ and not the absolute $\mathrm{W}_{\max }$, gender was not a significant predictor 
of approval. That may be due to that women in the firefighter population are likely more fit and not representative of the general female population. Nevertheless, due to the small number of females in this cohort, conclusions cannot be made.

In addition, TM test approval associated inversely with body weight. Reference equations for TM performance (expressed as $\mathrm{VO}_{2}$ max) indicate that age, body weight, and gender are independent predictors of test result [6o], which is in concordance with our findings.

The difference in the effect of body weight on CE and TM test approval is most probably related to the diverse natures of walking and cycling.

\section{Fitness evaluation in firefighters}

As discussed previously, the actual metabolic demands of firefighting have been studied by several research groups and the results vary. Many aspects of the tests contribute to the different outcomes, such as

- the evaluated tasks (from the most common tasks to the most exhausting, either combined as an entire firefighting operation or as individual tasks),

- the pacing (self-paced, time-limited, or paced by instructor),

- the evaluated physiological parameters (HR, ventilatory gases, rate of perceived exertion),

- the method of gas exchange measurement (direct or indirect, breath-by-breath or Douglas bag),

- the motivation of the test subjects, and

- the physical ability of the test subjects (e.g. at an intermediate rate of perceived exertion, subjects with a high level of aerobic capacity will execute tasks at a higher oxygen consumption level than test subjects with lower aerobic capacity).

Whether the most relevant measure of oxygen uptake is the absolute value or the weight-related value has been debated and should be considered in the context of the intended use of the test.

In simulated firefighting tasks, performance time has been shown to correlate with oxygen uptake; high weight-adjusted oxygen uptake correlated with a shorter time to complete the task [34, 36, 40]. Dreger and Petersen compiled average $\mathrm{VO}_{2}(\mathrm{ml} / \mathrm{kg} / \mathrm{min})$ values from these and additional studies measuring oxygen consumption during simulated firefighting, plotted them against the average work time, and found a significant linear relationship between weight-adjusted oxygen cost and work duration. The mean of the average $\mathrm{VO}_{2}$ values was $35 \mathrm{ml} / \mathrm{kg} / \mathrm{min}$ (range $27-41 \mathrm{ml} / \mathrm{kg} / \mathrm{min}$ ) [36]. 
Other studies of physical tests and simulated work tasks suggested that absolute $\mathrm{VO}_{2} \max (\mathrm{L} / \mathrm{min})$ values correlated better with work task performance than weight-adjusted $\mathrm{VO}_{2} \max (\mathrm{ml} / \mathrm{kg} / \mathrm{min})$ values [61]. von Heimberg et al. [40] found that the weight-adjusted maximal oxygen uptake $(\mathrm{ml} / \mathrm{kg} / \mathrm{min})$ did not differ significantly between fast and slow performance, but that the faster group had a higher absolute $\mathrm{VO}_{2}$ max, and that the variation in $\mathrm{VO}_{2}$ max could account for as much as $28 \%$ of the variance in total operation time. Differences in results may be due to the diverse requirements of the evaluated tasks, which ranged from heavy carrying and dragging to ladder climbing.

Current Swedish firefighter regulations regarding testing do not explicitly mention a specific level of oxygen uptake required for approval, but the former CE test required an oxygen uptake of $\sim 2.8 \mathrm{~L} / \mathrm{min}$. The preparatory work published along with the revised guidelines consider the oxygen uptake between the new TM test and the former CE test comparable, at least on a group level [62]. Our estimations for the CE test corresponded well with the absolute oxygen requirement specified for the CE test.

In this study, we estimated the metabolic requirement for the TM test to be significantly higher than for the CE test using both absolute and weight-adjusted numbers. Nevertheless, the estimated average oxygen expenditure of $38 \mathrm{ml} / \mathrm{kg} / \mathrm{min}$ for the standard TM test analysed in this study falls below the minimum level recommended by several authors. Besides, the estimated oxygen cost of the TM test yielded a mean value just above the average for simulated firefighting, which, if the estimations are accurate, leaves a negligible margin between actual oxygen consumption during firefighting and the minimal requirement for Swedish firefighters.

\section{Protective clothing}

As an indicator of the cardiovascular effort required for the two types of CWL test modalities, we studied the HR response, and found that the HR was significantly higher at the end of the TM test compared to the CE test, despite the higher age of the test subjects performing the TM test and the higher rate of test achievement. Thus, HR analysis indicated a higher cardiovascular strain during the TM test, but the difference is somewhat difficult to interpret due to the different testing conditions:

The protective clothing worn by firefighters on duty is rather unique and consists of layered thermal protective clothing, a helmet, boots, and a SCBA. The protective clothing has been shown to increase energy expenditure $\sim 20 \%$ for horizontal TM walking when compared to the same test performed wearing an athletic outfit [63]. The increase may be due to 
the extra weight of the protective clothing, but it exceeds what is expected from the theoretical predictions solely [63,64]. The fractional contribution of $20 \mathrm{~kg}$ of protective firefighting clothing and equipment for level TM walking was found to be $31 \%$ for absolute oxygen uptake and $26 \%$ for HR [65]. Despite weighing merely $2.4 \mathrm{~kg}$, heavy footwear contributed $\sim 11 \%$ of the additional oxygen uptake due to their location far from the centre of mass [66]. Although Swedish firefighters are not required to wear boots at the stipulated TM test, the remaining gear probably increases both the energy expenditure and the HR, as can be assumed from our data.

In summary, in the TM test for firefighters, the metabolic and HR increases appear to be related to the load carried and to the altered thermoregulation due to the protective clothing. However, the relative contributions of the load and the protective clothing to the energy expenditure and the cardiovascular strain remain unclear.

\section{Examples of international firefighter testing}

A proper firefighter test should distinguish between those who are fit enough and those who are not fit enough to do the job. Still, firefighter tests differ between countries and between fire departments in the same country.

\section{Aerobic capacity}

The present TM test protocol for a Swedish smoke diving firefighter is a modified version of the TM test developed by Smolader et al. [67] in which the firefighter wears smoke diving equipment and exercises in four 5 min steps. The final step is at an $8^{\circ}$ inclination at $4.5 \mathrm{~km} / \mathrm{h}$, and the average $\mathrm{VO}_{2}$ values were above $36 \mathrm{ml} / \mathrm{kg} / \mathrm{min}$ or $3 \mathrm{~L} / \mathrm{min}$ for the final step. Based on that, the Finnish recommendations from 2007 state that smoke diving firefighters should have an aerobic capacity of at least 36 $\mathrm{ml} / \mathrm{min} / \mathrm{kg}$ or $3 \mathrm{~L} / \mathrm{min}$. Direct measurement of respiratory gases during cardiopulmonary exercise testing is now recommended, but approval of a standardised smoke diving work task circuit is also accepted [68].

In Norway, fitness is also tested with a time-limited TM test in which the test firefighter wears a total of $23 \mathrm{~kg}$ of protective equipment. The TM inclination is marginally lower $\left(7^{\circ}\right)$, but the TM speed is higher $(5.6 \mathrm{~km} / \mathrm{h})$ [69].

The recommended minimum aerobic capacity for Brittish firefighters is $42 \mathrm{ml} \mathrm{O} 2 / \mathrm{kg} / \mathrm{min}$, although no specific testing protocol or methodology is required [70].

The aerobic capacity of American firefighters should be evaluated annually by prediction of the $\mathrm{VO}_{2}$ max by either of two submaximal tests: 
the Wellness-Fitness Initiative (WFI) TM protocol or the WFI stepmill protocol. There is no nationally required minimum level of fitness for duty, but MET values below 12, 10, and 8 METs, which correspond to $\sim 42$, 35 , and $28 \mathrm{ml} / \mathrm{kg} / \mathrm{min}$, respectively, lead to initiation of different fitness improvement programmes and, if below 8 METs, possible restriction from certain essential job tasks [71].

\section{Other physical abilities}

Several countries, such as Norway and the United States, also include standardised tests for muscular strength and endurance in the physical evaluation $[69,71]$.

To extend the physical evaluation to include other physical, workrelated abilities in addition to aerobic power, multiple attempts have been made to develop standardised field tests appropriate for the evaluation of firefighters $[61,72,73]$ as a complement to or as a possible future substitute for the current aerobic capacity tests, although yet not implemented in national regulations.

\section{Particular considerations on test selection}

The importance of a sufficiently high physical capacity to perform tasks during firefighting emergencies is unquestionable. The key questions in firefighter testing are: What is measured?, How is it measured?, and How relevant is the result?

From the perspective of both the employer and employee, the relevance of the test in relation to work performance is crucial. First, as discussed above, the aerobic capacity required to complete the test must correspond to the aerobic requirements of most firefighting tasks to ensure safe and efficient manoeuvres. Second, the test result must correspond to the ability to actually work as a firefighter. In other words, a test result with poor correlation to performance during firefighting operations may favour subjects with irrelevant abilities and may discriminate against subjects who perform poorly on the test but who would have been able to manage the work.

Many exercise tests aim to measure or estimate the maximal oxygen uptake or assure a certain minimum level. As a physiological marker and health indicator, oxygen uptake provides useful information. However, due to the intermittent nature of most firefighting tasks, oxygen uptake fluctuates and interpretation of mean values overlooks periods of supramaximal intensities with anaerobic contributions. The drawback of using solely peak $\mathrm{VO}_{2}$ or a threshold $\mathrm{VO}_{2}$ value as a criterion for pass/fail is the assumption that oxygen uptake in firefighters can predict occupationally relevant performance. Although peak $\mathrm{VO}_{2}$ associates strongly with per- 
formance in sports, it is not the only factor that determines performance. Firefighting may be even more susceptible to external factors than athletic performance.

The exercise test examined in this dissertation primarily evaluate aerobic capacity. Additional factors such as heat tolerance, lower limb muscular endurance, grip strength, arm/leg/core strength, flexibility, psychological stress tolerance, and ergonomy, that would affect overall firefighting performance are not evaluated to the same extent in the standard testing. These factors make firefighter requirements and firefighter testing fairly unique. Although definitely relevant for the testing of firefighters, assessment beyond cardiovascular fitness is outside the scope of this dissertation. However, the firefighter TM test includes indirect assessment of characteristics valuable for firefighting performance other than merely cardiorespiratory fitness, which increases its practical usefulness.

Our results indicate that changing the regulations for fitness testing of Swedish firefighters from CE-based to TM-based testing may have lowered the threshold for approval and permitted a slight reduction in the average cardiorespiratory fitness level of Swedish firefighters. In addition, the aerobic demands for the analysed tests, which have been previously published and calculated in this study, are in the lower range of the recommendations for minimal aerobic capacity for firefighters, thus there is only a small margin for further lowering of the threshold. Although the association between firefighting performance and test results could not be addressed in this study, potential lowering of the fitness threshold merits further attention.

We have found that different tests favour different body compositions, for example, the TM test is unfavourable for heavier firefighters. Speculatively, heavier firefighters who achieve TM test approval perform a large amount of total work during the test and may have an increased ability to managing the occupationally heavier moments when compared to the lighter individuals who can pass the TM test with a lower total oxygen uptake that may challenge their ability to complete the physically heavier tasks. A similar phenomenon was observed in a study that compared an extended TM test to a work-simulating test in Norway [72].

In summary, use of a more firefighter-specific fitness test, such as the TM test examined here, seems favourable, but its configuration regarding load, speed, and inclination may need to be reviewed to assure that the minimum threshold for firefighter approval is high enough. 


\section{Exercise capacity and age}

A decrease in exercise capacity with age has been described previously [74-76] and was confirmed by our data. For firefighters, it has been suggested that the decline in exercise capacity is compensated for by experience. Danielsson et al. [77] examined typical firefighting activities performed by recruits and firefighters of different ages with different work experience (age coincided with years of experience) and found a successive increase in the duration to complete the test course as age increased, although the rate of perceived exertion was similar.

Professional firefighters are requested to maintain their fitness by physical exercise at work, but the decline in exercise capacity with age observed in this firefighter cohort agrees with that there should be a 'fitness margin' for new, young employees to compensate for their successive decline in the future, as in the current Swedish guidelines. 


\section{Exercise testing for identification of subclinical IHD in low-risk populations}

\section{Pre-test probability}

As already stated in the Methods section, it is crucial to analyse the characteristics of a test and the tested population using a Bayesian approach for the test to be useful.

The pre-test probability of stable angina, i.e. the probability of finding significant CAD by catheterisation, is usually based on age, sex, and characteristics of symptoms. The original American College of Cardiology/American Heart Association (ACC/AHA) guidelines for management of patients with chronic stable angina [78] defined the pre-test probability percentages based on the early estimates of Diamond and Forrester [79]. The European Society of Cardiology (ESC) guidelines [9] used modified predictive effects of the same parameters in an updated DiamondForrester model, which adjusted for changes in the distribution of risk factors over the past decades (i.e. the declining prevalence of hypertension, hyperlipidaemia, and tobacco use in the overall population) and for differences between American and European populations [80].

According to the ESC guidelines, a pre-test probability of $<15 \%$ is considered low. In subpopulations with pre-test probabilities below the threshold of $15 \%$, performing no test will generate fewer incorrect diagnoses than using a test with a sensitivity and specificity of $85 \%$. Thus, subjects who have a low $(<15 \%)$ probability of significant CAD should have their cardiovascular risk factors adjusted based on a risk score assessment [81], but stress testing is discouraged according to the guidelines [9]. It should be emphasised that these risk estimates apply to subjects presenting with chest discomfort, which was not the case for the firefighters in this study. Males aged 35, 45, or 55 years old with atypical symptoms of angina are classified as having a pre-test probability of $18 \%, 25 \%$, or $34 \%$ respectively [9]. Substantially lower pre-test probabilities can be expected in our asymptomatic cohort.

\section{ST depression}

More than $20 \%$ of subjects in our asymptomatic cohort developed an ST depression of at least $0.1 \mathrm{mV}$ in at least one lead by the end of exercise. In $10 \%$ of the population, the ST depression was horizontal or downsloping. 
In a sample of the Kuopio Ischemic Heart Disease Risk Factor Study that analysed $\sim 1$,80o Finnish men aged 42-60 years with no history of myocardial infarction or angina pectoris, the prevalence of asymptomatic horizontal/downsloping ST depression during exercise was 11\% and comparable to our cohort. The exercise-induced ST depression was found to be associated with an increased risk for SCD during an 18-year follow-up (HR 2.1, 95\% CI 1.2-3.9), although with a sensitivity of merely $18 \%$. The risk increase was even higher in the presence of other conventional risk factors, such as smoking or hypercholesterolemia [82]. Interestingly, when adding fitness level to the analysis, exercise-induced ST depression did not associate with an increased adjusted risk for SCD when compared to subjects with matching cardiorespiratory fitness but no exerciseinduced ST depression [83], which illustrates the challenge of screening fit individuals.

Other studies have also found a higher long-term ( $>10$ years) risk for mortality and morbidity due to IHD in apparently healthy men with exercise-induced ST depression than in individuals with normal ExECG responses [84]. On the contrary, in the Multiple Risk Factor Intervention Trial (MRFIT), the prognostic value of exercise tests in asymptomatic subjects was studied for a shorter follow-up time (7 years), and no significant increase in CAD mortality risk was observed for individuals with a horizontal or downsloping ST depression [85].

All of these referred studies focused on the prognostic rather than the diagnostic impact of exercise-induced ST abnormalities in asymptomatic individuals, whereas the repeated firefighter testing aims for diagnosis of subclinical disease that would have implications on the suitability for smoke diving duty.

The diagnostic value of ST-segment depression in asymptomatic subjects is more difficult to assess because few asymptomatic patients undergo coronary angiography. Also, in studies with reduced work-up bias, the sensitivity of exercise-induced ST depression for diagnosing IHD has been shown to be low [86]. In fact, a rapidly upsloping ST depression may even be a benign sign of IHD with a lower long-term risk of mortality from CAD compared with a normal ST-segment response [87].

\section{ST/HR variables}

In addition to standard ST evaluation during ExECG, we adjusted the ST deviation to the HR during the work phase (ST/HR index and ST/HR slope) and during the work and rest phases combined (rotation and area of the ST/HR loop). 
In the previous MRFIT study of asymptomatic subjects, an abnormal ST/HR index associated with increased cardiac risk, whereas, according to standard criteria, an abnormal exercise test did not associate with increased cardiac risk [85]. Another study that included patients with suspected CAD found that the ST/HR index did not improve the diagnostic accuracy of the exercise test to identify the presence or severity of CAD when compared to ST-segment depression analysis [88].

In our study, only in V4 and for no other lead, development of an ST depression associated with an increased risk for IHD. For all of the ST/HR variables, an abnormal test result in three or more leads associated with IHD (Tables 8 and 9) indicating an enhancement of the predictive value. For the clockwise-rotated ST/HR loops, significant increases in the odds ratios for IHD were consistent across most of the analysed leads, but the risk estimates did not reach significance in the inferior leads aVF and III where the frequency of clockwise-rotated loops was higher than in the other leads.

The area encircled by the ST/HR loop is known to be more negative in patients with IHD than in healthy controls $[49,89]$ and the ST/HR hysteresis has been shown to be superior to maximal ST depression in the diagnosis of IHD [51], also in subjects with "equivocal" exercise ECG results (horizontal or upsloping ST depression) [90]. However, both studies analysed populations with clinically suspected angina pectoris, thus they had higher pre-test probabilities than our firefighter cohort.

There are no established cut-off limits for the ST/HR loop area that indicate ischaemia, but a partition value of $-15 \mu \mathrm{V}$ has been suggested as the cut-off for the lead with the minimum value for each test subject [91]. Our lead-specific NA cut-off values were spread around zero $(-18$ to +34$)$ with positive values in all of the precordial leads and in one of the extremity leads. Viik et al. studied lead-specific properties of the ST/HR variables and discouraged fixed cut-off points for ECG leads in general, but found that interlead differences were relatively small for ST/HR hysteresis, [51].

Although ST/HR variables appeared to be better predictors of IHD then ST depression in our asymptomatic cohort, the AUCs in ROC analyses were modest. With some exceptions (ST/HR slope in II and NA in -aVR), the AUCs were not significantly different from $50 \%$ in the extremity leads. The anterolateral chest leads $\left(\mathrm{V}_{3}-\mathrm{V}_{5}\right)$ had the highest AUC values for most variables, especially the $\mathrm{ST}_{\max }$ and $\mathrm{ST} / \mathrm{HR}$ index, but for no variable or lead the AUC was higher than 73\%. A previous study have found ROC AUCs of 86-92\% for the ST/HR variables in males, being highest for the ST/HR hysteresis [91]. The authors had selected the most negative ST/HR loop area for analysis, but using the same method, we did not reach the same results in our population. 
Our ROC curve results show the lack of a variable that combines high sensitivity and specificity in our asymptomatic cohort, which implies both false-positive and false-negative results in a screening situation as the firefighter medical evaluation.

\section{Firefighters and cardiovascular risk}

In the United States, the leading cause of duty-related death among firefighters is SCD. A recent nationally representative sample of firefighter autopsies revealed evidence of both $\mathrm{CAD}$ and left ventricular hypertrophy in more than 4/5 of the cases. Cardiomegaly, coronary artery stenosis, and prior myocardial infarction were all strong independent predictors of duty-related cardiac death [92]. Swedish authorities do not keep systematic records on causes of death, but they reported that cardiovascular conditions are very rare causes of on-duty deaths [93]. The cardiovascular risk profile of American firefighters who suffered SCD differed from our subgroup of firefighters who were diagnosed with IHD. The American firefighters had a higher body mass $(104.5 \pm 22.0 \mathrm{~kg})$ and BMI $(31.8 \pm 5.8$ $\mathrm{kg} / \mathrm{m}^{2}$ ), and $59 \%$ were obese. These differences in risk profiles probably contribute to differences in mortality and risk.

Examples of other strategies to evaluate the cardiovascular health of firefighters have been found internationally, and many of them involve more complex algorithms than the current Swedish standard. According to the Norwegian Labour Inspection Authority, the baseline medical evaluation of Norwegian firefighters includes lung function testing, resting ECG to reveal signs of cardiomyopathy, BP, and total cholesterol. Total cholesterol and BP are scored for cardiovascular risk evaluation according to a national risk score system (NORRISK 2). Scores indicating $>2 \%$ probability of myocardial infarction within 10 years warrant further cardiac evaluation [69].

According to the 2018 edition of the National Fire Protection Association (NFPA) standards, the annual medical evaluation of American firefighters should include 2-year and 10-year risk assessments for risk of $\mathrm{CAD}$, as well as risk stratification for stroke and resting ECG for firefighters above the age of 40. Recommended tools for risk stratification are the ACC/AHA 10-year Heart Risk Calculator and the Framingham Heart Study 2-year risk prediction score, including age, sex, race, blood lipid profile, systolic blood pressure, anti-hypertensive medication, and smoking status. Based on the risk stratification, subjects with an intermediate risk should undergo exercise testing with or without additional imaging, and subjects with a high risk should be referred to a cardiologist for further evaluation and treatment [71]. 


\section{Cardiac screening in other populations}

Although legal and safety perspectives may differ between the occupational and voluntary ways that employees with a physically requiring work and athletes strain their hearts, identification of subclinical heart disease is desirable for both groups, and lessons could be learned from studying other populations.

\section{Athletes}

Master athletes are comparable to firefighters in that they are both asymptomatic populations with a generally low cardiovascular risk and a better than average fitness level. They also both regularly perform cardiac activities above sedentary levels.

A high cardiorespiratory fitness level is associated with reduced mortality and reduced risk of cardiovascular disease largely due to its beneficial effects on modifiable risk factors, such as blood pressure, lipid profile, and body weight [94]. Nevertheless, SCD does occur also in the physically active population. The main cause of SCD in veteran athletes is CAD [95], but the importance of the ExECG in the prevention of cardiac events among sportsmen is controversial.

A systematic review of ExECGs for more than 32,000 asymptomatic athletes found that the mean prevalence of an ExECG positive for IHD was $1 \%$ (range $0-29 \%$ ) with a higher mean prevalence in older subgroups [96]. However, the prevalence of cardiac disease was low and the authors concluded that the mean PPV for IHD was merely 9\%.

Dores et al. studied male veteran athletes $>40$ years of age and found that conventional methodology based on clinical CV risk factors and ExECG was poor at identifying significant subclinical CAD, but that the inclusion of more objective markers, particularly data derived from cardiac CT, was promising for more accurate risk stratification of these athletes [97].

The prevalence of ST abnormalities during maximal exercise and/or recovery in a cohort of asymptomatic leisure athletes aged 30-60 years was $\sim 5 \%$ [98]. This prevalence is comparable to our results given that ST abnormalities were defined as significant ST depression in $\geq 2$ leads including at least one precordial lead. In the subgroups of athletes with ST abnormalities, $14 \%$ were diagnosed with significant CAD and $16 \%$ with origin/course anomalies of the coronary arteries by coronary CT angiography.

Strategies to reduce the risk of cardiac events among leisure athletes are included in a position stand from the European Association of Cardiovascular Prevention and Rehabilitation [99]. Self-assessment of the physical activity level and modifiable risk factors is promoted for screening of 
large populations and maximal exercise testing of senior/adult individuals is advocated in case of an increased risk of coronary events.

\section{Air crew}

The medical assessment of aircrew and firefighter shares the needs to evaluate asymptomatic employees to avoid the disastrous consequences of a ruptured, previously unknown, coronary plaque.

For aircrew, a three-step approach to CAD risk assessment has recently been suggested. The algorithm begins with population-appropriate risk stratification and, for pilots above 40 years of age, a resting ECG. Subjects at increased risk should go through enhanced screening with cardiac CT. Lastly, if the enhanced screening indicates high risk, second line investigations including functional ischaemia testing and potentially invasive coronary angiography, follow. The aircrew recommendation also states that ExECG may be added after performing the cardiac CT, but that it is discouraged as a sole screening tool for CAD [100].

Implementing a similar model for firefighters is attractive. As stated above, several countries already use risk stratification as a first step prior to any medical testing. However, apart from selecting an appropriate riskstratification model, clinical interpretation of enhanced screening methods among physically active firefighters requires specific considerations because, for example, CT coronary artery calcium scores have been shown to be higher in athletes than in sedentary individuals [101].

\section{Clinical value of exercise testing in a low-risk population}

The utility of a screening test is a function of both test performance and the possibility to intervene successfully to improve outcomes for patients with positive test results. Both the Atenolol Silent Ischemia Study (ASIST) [102] and the Asymptomatic Cardiac Ischemia Pilot (ACIP) [103] studies suggest that modern pharmaceutical and revascularisation therapies for patients with mild cardiovascular symptoms and ECG-documented ischaemia improve outcomes in terms of survival rate.

ExECG is non-invasive, non-radiant, has good availability, and is relatively low cost, thus an attractive methodology. However, in this study and in numerous previous studies, standard ExECG criteria failed to consistently and correctly separate healthy individuals from individuals with subclinical disease or increased risk. We found that an extended analysis of ExECG results predicted risk slightly better, but is still unsatisfactory for clinical use. If clinicians are unaware of the limited ability of the ExECG to accurately identify or exclude disease, ExECG testing may not be useful in the assessment of subclinical IHD. In fact, testing may do harm 
if the number of false test results is higher than the number of correct test results.

Thus, the greatest potential benefit of ExECG screening in asymptomatic populations would probably be for sedentary intermediate-risk persons because the identification of abnormalities could shift them into a high-risk group, which would benefit from additional interventions. Within the firefighter cohort, only a minor subset of individuals would be selected for testing using this pre-test criteria.

In addition to the ST segment, other parameters from the exercise test, such as chronotropic incompetence, impaired HR recovery, and decreased exercise capacity, impact future risk [45]. These variables may be of long-term or short-term prognostic importance, but for the purpose of identifying asymptomatic, clinically important $\mathrm{CAD}$, such as in the firefighter assessment, the clinical impact is unclear.

\section{ST depression in the absence of known CAD}

\section{Physiological factors}

In our study, exercise-induced ST depression in the absence of CAD associated primarily with a pronounced increase in HR. Subjects with falsepositive exercise tests have previously been characterised with a high peak exercise HR, absence of exercise-induced chest pain, and a markedly downsloping PR segment [104]. An exaggerated P wave repolarisation displaced into the ST segment is thus a plausible cause of a false-positive ST-segment depression also in the asymptomatic males in the studied firefighter cohort.

Non-ischaemic ST depression may also be caused by intraventricular conduction abnormalities and left ventricular hypertrophy [5], although individuals with these conditions were excluded from the present study.

\section{Pathological factors}

CAD reflects obstructions in the blood flow of the epicardial arteries of the heart as seen on a coronary angiogram. Absence of significant arterial stenosis may be interpreted as absence of IHD, although the entire vasculature and the functional blood flow are not visible in the angiogram. Abnormalities in the function and structure of the coronary microcirculation can thus be a cause of myocardial ischaemia in patients without obstructive atherosclerosis. Exercise-induced ST depression in subjects with normal angiograms may be caused by microvascular dysfunction, especially if the ST depression is horizontal or downsloping [105]. 
Probable causes of microvascular dysfunction in the absence of obstructive CAD are endothelial dysfunction, smooth muscle cell dysfunction, and vascular remodelling leading to impaired vasodilatation capacity and/or increased vasoconstrictor tone. Non-ischaemic heart disease may also cause microvascular dysfunction by extramural compression [106]. The correlation of increased prevalence of non-coronary ST depression with increased age in our cohort could reflect the development of pathophysiological processes over time, although the asymptomatic state of the test subjects decreases the probability of this occurrence.

Coronary microvasculature function can be measured by quantification of myocardial blood flow and the coronary flow reserve, which is defined as the magnitude of the increase in coronary flow that can be achieved from the resting state to maximal coronary vasodilation [107]. Non-invasive techniques, such as stress positron-emission tomography, cardiovascular magnetic resonance, myocardial perfusion imaging [107], and transthoracic Doppler echocardiography [105], to understand and evaluate coronary microvascular dysfunction and coronary flow reserve are being developed rapidly.

Although microvascular dysfunction is an acknowledged cause of chest pain in patients without an epicardial coronary obstruction, it has not been extensively studied in low-risk, asymptomatic subjects with exercise-induced ST depression and minimal cardiovascular comorbidity, such as is found in our firefighter cohort. Such studies could help explain exercise-induced ST depression in asymptomatic individuals. 


\section{Methodological limitations}

The studies in this dissertation were performed on all of the available firefighters in a geographic province in Sweden.

\section{Paper I}

Paper I compares the physiological response to loaded TM walking and $\mathrm{CE}$ by estimating the oxygen cost. Despite using the most appropriate equations, the oxygen requirements presented in this study do not take all parameters, such as heat stress from the protective clothing and emotional stress from the testing situation, into account.

The use of test modalities in this retrospective analysis has changed over time (Fig. 7), and because individuals were not normally sent for two parallel exercise capacity tests, direct comparison of different modality test results performed by the same individual was not possible. Instead, using a previously published equation, maximal exercise tests with successively increasing workloads were converted to the corresponding workload that the individual was expected to maintain for $6 \mathrm{~min}\left(\mathrm{P}_{\max } 6^{\prime}\right)$. We aimed to assess the accuracy of this conversion by comparing true $200 \mathrm{~W}$ CWL tests with converted CE ramp tests as described in the Results section. The comparison included available tests performed within 2 years and showed a misclassification in $15 \%$ of the cases, i.e. when the CWL test was accomplished, but the calculated $\mathrm{P}_{\max } 6$ ' fell below $200 \mathrm{~W}$. In all of those cases, the CWL test was performed first, which may explain part of the difference by a small physiological decline in work capacity. We do not know whether other factors, such as orthopaedic problems or recent infections, impaired the exercise capacity or if the difference was due to an imperfect equation.

\section{Paper II}

Paper II contains a methodological description of large-scale data acquisition and transfer from a clinical ExECG database to a research database for statistical analysis. Extracting, sorting, and processing of data was performed in parallel with quality control and troubleshooting of software development. This workflow was appropriate for identification of inadequate coding in the newly developed software and areas of improvement when raw data was subject to recurrent errors. However, the simultaneous development of the software and the setup of the research database limited the possibilities to perform in-depth analyses on how the processing of the data affected the results, such as comparison of results before and after data processing. For example, the majority of the subjects 
performed multiple tests, thus when selecting tests for the different studies, a test that failed to meet the quality criteria was substituted with the next consecutive test performed by the same subject.

\section{Paper III and IV}

Paper III and IV relied on accurate categorisation of patients as having or not having IHD. The categorisation was based on results from retrospective, available cardiac imaging studies, including coronary angiography, myocardial scintigraphy, cardiac magnetic resonance imaging, and coronary computed tomography. IHD was defined as at least one positive result from any of these test modalities. The majority of subjects in the IHD group (11 out of 12) showed significant stenosis by coronary angiography even though they may have first been tested with another imaging modality.

Obviously, a prospective study protocol would have enabled a more uniform procedure, including the selection of the imaging modality, the time frame for the imaging studies, and the definition of pathology, for all of the study subjects. There are a few main considerations regarding the selected methodological approach.

First, given the retrospective design, we considered it likely that subjects diagnosed with clinically important IHD at some point during the testing or follow-up period would present with signs or suffer from symptoms that would motivate imaging and subsequent classification into the correct outcome group. However, in some cases, the time between the test and the positive imaging result was prolonged and may have allowed for development of the disease from a subclinical state to an overt state.

Second, imaging was restricted to subjects with abnormal ExECGs who were referred for further evaluation and those who sought medical care outside of the screening programme. A few of the imaging results demonstrated atheromatotic lesions of non-significant extent. Although non-significant findings may have contributed to abnormal ExECG responses, any such associations could not be assessed in this study because the majority of coronary vessels in the non-IHD group were not visually evaluated.

Third, although coronary angiography normally determines the need for revascularisation, it does not assess microvascular function, which could have been impaired in patients with exercise-induced ST depression despite negative (or non-significant) findings on the coronary angiogram.

Finally, it is worth mentioning that the absolute numbers of subjects with IHD, as well as with hypertension, hyperlipidaemia, or diabetes were low, and this may have contributed to the non-significant results, low-risk estimates, and large confidence intervals in the statistical analyses. Be- 
cause our study population included all of the firefighters in an entire county, power calculation prior to sample size determination was not feasible. However, because the study reflects the reality of clinically performed ExECG tests aimed to detect subclinical IHD, the lack of significance is illustrative of real-world assessments. 


\section{CONCLUSIONS}

The main findings of the studies in this dissertation were the following:

\section{Paper I}

When comparing two exercise testing modalities in firefighters, we found that despite a higher estimated oxygen cost and a higher measured HR response during the TM test than during the $\mathrm{CE}$ test, it was more common to pass the TM test but to fail the supposedly equivalent $\mathrm{CE}$ test rather than vice versa.

Lower age and tall stature predicted approval for both the CE and TM tests, whereas lower body weight only associated with approval for the TM test.

\section{Paper II}

This methodological paper contains descriptions of procedures and software development to acquire data from a large clinical ExECG database as well as the subsequent processing steps for automated error checking and analysis of new parameters.

Increasing the accessibility of data enabled large-scale testing of possible diagnostic variables, which may impact the value, interpretation, and strategy for future exercise testing in different subgroups.

\section{Paper III}

Exercise-induced ST depression was common in the asymptomatic firefighter cohort analysed, but the association between ST depression and clinical IHD was weak. ST analysis combined with HR data during the work phase (ST/HR index and ST/HR slope) tended to assess IHD risk better than ST depression alone, by increasing the number of leads with predictive ability. When the recovery phase was included in the ST/HR loop analysis, a predictive ability to identify IHD risk was seen in more leads. However, the added value was still low because none of the analysed variables had both high sensitivity and high specificity in the ROC analysis, indicating that both false-negative and false-positive test results remain an issue in this type of population.

Thus, if ExECG is to be performed in asymptomatic individuals, ST/HR variables could probably be given more importance. 


\section{Paper IV}

In firefighters with no clinical evidence of CAD, exercise-induced ST depression was more common with increasing age and associated with a high age-adjusted peak HR and a large age-adjusted HR increase. Remarkably, neither a high end-exercise blood pressure nor traditional cardiovascular risk factors, including hypertension, hyperlipidaemia, and diabetes, associated with exercise-induced ST depression. Whether the effect of age and $\mathrm{HR}$ on exercise-related changes was purely electrophysiological or secondary to microvascular or structural myocardial variations remains to be elucidated. 


\section{CLINICAL IMPLICATIONS AND FUTURE PERSPECTIVES}

When performing ExECG on Swedish firefighters, we found that as many as one out of five of them developed an ST depression, which is the standard indicator of IHD. For many firefighters with an abnormal ECG response, the test result led to referral to a cardiologist for evaluation of suspected IHD. If IHD was confirmed, it would require medical treatment and would lead to discontinuation of smoke diving duty. However, only a few of the firefighters in our cohort were diagnosed with IHD during the testing period or during the reasonably long follow-up, and a large proportion of the firefighters who underwent cardiac imaging did not benefit from it. At the same time, the current testing system failed to identify many of the individuals with a truly increased risk, and who eventually developed IHD.

Our aim to evaluate ST/HR variables to improve interpretation of ExECG results resulted in minor improvements, but the combination of sensitivity and specificity remained unsatisfactorily low. This strongly reinforces doubt of the clinical relevance of performing repeated ExECGs on firefighters or similar unselected, asymptomatic populations.

Instead, other strategies for identifying subclinical IHD and high-risk subjects should be sought for. A model that can predict the pre-test probability of stable CAD in an asymptomatic, physically active population and that can identify individuals who are at increased risk and who may benefit from further diagnostic investigation has yet to be described for firefighters. Integration of additional clinical data in a systematic riskstratification process prior to clinical testing is recommended as an improvement to the current medical evaluation of asymptomatic firefighters.

Further, our analysis of firefighter fitness test results found a higher approval rate for the TM test than for the CE test. An approved TM test in combination with failure to reach $250 \mathrm{~W}$ during the CE test may allow for authorisation of firefighters with maximal oxygen uptakes lower than 2.8 $\mathrm{L} / \mathrm{min}$. Over time, there is thus a risk of lowering the physical fitness level of Swedish firefighters in terms of absolute oxygen uptake.

It would be of interest to investigate the actual oxygen uptake required to complete the current firefighter TM fitness test and to compare 
those values with the oxygen uptake values measured during firefighting simulations. Also, evaluation of the firefighting performance of firefighters who pass the TM test but not the supposedly equivalent CE test would be of interest to investigate whether the change in the test modality and the possible lowering of oxygen uptake requirements have an actual impact on the performance of the Swedish fire brigade. 


\section{REFERENCES}

1. Goodwill, A.G., et al., Regulation of Coronary Blood Flow. Compr Physiol, 2017. 7(2): p. 321-382.

2. King, R.J. and P.J. Grant, Diabetes and cardiovascular disease: pathophysiology of a life-threatening epidemic. Herz, 2016. 41(3): p. 184-92.

3. Hurtubise, J., et al., The Different Facets of Dyslipidemia and Hypertension in Atherosclerosis. Curr Atheroscler Rep, 2016. 18(12): p. 82.

4. Libby, P. and P. Theroux, Pathophysiology of coronary artery disease. Circulation, 2005. 111(25): p. 3481-8.

5. Pollehn, T., et al., The electrocardiographic differential diagnosis of ST segment depression. Emerg Med J, 2002. 19(2): p. 129-35.

6. Diercks, D.B., et al., Electrocardiographic manifestations: electrolyte abnormalities. J Emerg Med, 2004. 27(2): p. 153-60.

7. Slavich, G., et al., [Pseudoischemic ST-segment due to atrial repolarization during exercise test. Review of the literature, diagnostic criteria and personal experience]. G Ital Cardiol (Rome), 2006. 7(10): p. 670-4.

8. Okin, P.M., J. Chen, and P. Kligfield, Effect of baseline ST segment elevation on test performance of standard and heart rate-adjusted ST segment depression criteria. American heart journal, 1990. 119(6): p. 1280-6.

9. Montalescot, G., et al., 2013 ESC guidelines on the management of stable coronary artery disease: the Task Force on the management of stable coronary artery disease of the European Society of Cardiology. Eur Heart J, 2013. 34(38): p. 2949-3003.

10. Einthoven, W., Weiteres uber das Elektrokardiogram. Arch Ges Physiol, 1908. 122(12): p. 517-84.

11. Chaitman, B.R., The changing role of the exercise electrocardiogram as a diagnostic and prognostic test for chronic ischemic heart disease. J Am Coll Cardiol, 1986. 8(5): p. 1195-210.

12. Borer, J.S., et al., Limitations of the electrocardiographic response to exercise in predicting coronary-artery disease. $\mathrm{N}$ Engl $\mathrm{J}$ Med, 1975. 293(8): p. 367-71.

13. Froelicher, V.F., Jr., et al., Angiographic findings in asymptomatic aircrewmen with electrocardiographic abnormalities. Am J Cardiol, 1977. 39(1): p. 32-8.

14. Gianrossi, R., et al., Exercise-induced ST depression in the diagnosis of coronary artery disease. A meta-analysis. Circulation, 1989. 80(1): p. 87-98. 
15. Banerjee, A., et al., Diagnostic accuracy of exercise stress testing for coronary artery disease: a systematic review and meta-analysis of prospective studies. International journal of clinical practice, 2012. 66(5): p. 477-92.

16. Kesteloot, H., S. Sans, and D. Kromhout, Dynamics of cardiovascular and all-cause mortality in Western and Eastern Europe between 1970 and 200o. Eur Heart J, 2006. 27(1): p. 107-13.

17. Task Force Members, et al., 2013 ESC guidelines on the management of stable coronary artery disease: the Task Force on the management of stable coronary artery disease of the European Society of Cardiology. Eur Heart J, 2013. 34(38): p. 2949-3003.

18. Okin, P.M. and P. Kligfield, Heart rate adjustment of ST segment depression and performance of the exercise electrocardiogram: a critical evaluation. Journal of the American College of Cardiology, 1995. 25(7): p. 1726-35.

19. Elamin, M.S., et al., Prediction of severity of coronary artery disease using slope of submaximal ST segment/heart rate relationship. Cardiovascular research, 1980. 14(12): p. 681-91.

20. Schiariti, M., et al., ST/HR slope and improved exercise ECG detection of myocardial ischemia in patients with suspected coronary artery disease. J Electrocardiol, 1991. 24(4): p. 307-14.

21. Detrano, R., et al., Exercise electrocardiographic variables: a critical appraisal. Journal of the American College of Cardiology, 1986. 8(4): p. 836-47.

22. Kligfield, P. and P.M. Okin, Heart rate adjustment of ST depression in patients with coronary disease and negative standard exercise tests. J Electrocardiol, 1999. 32 Suppl: p. 193-7.

23. Morise, A.P. and R.D. Duval, Accuracy of ST/heart rate index in the diagnosis of coronary artery disease. Am J Cardiol, 1992. 69(6): p. 603-6.

24. Kligfield, P., O. Ameisen, and P.M. Okin, Heart rate adjustment of ST segment depression for improved detection of coronary artery disease. Circulation, 1989. 79(2): p. 245-55.

25. Okin, P.M., et al., Heart rate adjustment of exercise-induced ST segment depression. Improved risk stratification in the Framingham Offspring Study. Circulation, 1991. 83(3): p. 866-74.

26. Okin, P.M., O. Ameisen, and P. Kligfield, Recovery-phase patterns of ST segment depression in the heart rate domain. Identification of coronary artery disease by the rate-recovery loop. Circulation, 1989. 80(3): p. 533-41.

27. Lehtinen, R., et al., Accurate detection of coronary artery disease by integrated analysis of the ST-segment depression/heart rate patterns during the exercise and recovery phases of the exercise electrocardiography test. The American journal of cardiology, 1996. 78(9): p. 1002-6. 
28. Åstrand, P.O. and I. Ryhming, A nomogram for calculation of aerobic capacity (physical fitness) from pulse rate during sub-maximal work. J Appl Physiol, 1954. 7(2): p. 218-21.

29. Brauer, K., L. Jorfeldt, and O. Pahlm, eds. Det kliniska arbetsprovet. 2003, Studentlitteratur: Lund.

30. Smith, D.L., T.S. Manning, and S.J. Petruzzello, Effect of strenuous live-fire drills on cardiovascular and psychological responses of recruit firefighters. Ergonomics, 2001. 44(3): p. 244-54.

31. Kales, S.N., et al., Firefighters and on-duty deaths from coronary heart disease: a case control study. Environmental health : a global access science source, 2003. 2(1): p. 14.

32. Ekberg, J., Personal communication. April 2017, Swedish Work Environment Authority.

33. Gledhill, N. and V.K. Jamnik, Characterization of the physical demands of firefighting. Can J Sport Sci, 1992. 17(3): p. 207-13.

34. Holmer, I. and D. Gavhed, Classification of metabolic and respiratory demands in fire fighting activity with extreme workloads. Applied ergonomics, 2007. 38(1): p. 45-52.

35. Bilzon, J.L., et al., Characterization of the metabolic demands of simulated shipboard Royal Navy fire-fighting tasks. Ergonomics, 2001. 44(8): p. 766-80.

36. Dreger, R.W. and S.R. Petersen, Oxygen cost of the CF-DND fire fit test in males and females. Applied physiology, nutrition, and metabolism $=$ Physiologie appliquee, nutrition et metabolisme, 2007. 32(3): p. 454-62.

37. Elsner, K.L. and F.W. Kolkhorst, Metabolic demands of simulated firefighting tasks. Ergonomics, 2008. 51(9): p. 1418-25.

38. Lusa, S., et al., Physiological responses of firefighting students during simulated smoke-diving in the heat. Am Ind Hyg Assoc J, 1993. 54(5): p. 228-31.

39. O'Connell, E.R., et al., Energy costs of simulated stair climbing as a job-related task in fire fighting. J Occup Med, 1986. 28(4): p. 2824.

40. von Heimburg, E.D., A.K. Rasmussen, and J.I. Medbo, Physiological responses of firefighters and performance predictors during a simulated rescue of hospital patients. Ergonomics, 2006. 49(2): p. 111-26.

41. Dreger, R.W., R.L. Jones, and S.R. Petersen, Effects of the selfcontained breathing apparatus and fire protective clothing on maximal oxygen uptake. Ergonomics, 2006. 49(10): p. 911-20.

42. The Swedish Work Environment Authority, The Swedish Work Environment Authority's Statute Book, Occupational medical supervision AFS 2005:06. 2005, Elanders Gotab: Stockholm.

43. Swedish National Board of Occupational Safety and Health, AFS 1986:6. 1986. 
44. Megnien, J.L. and A. Simon, Exercise tolerance test for predicting coronary heart disease in asymptomatic individuals: $A$ review. Atherosclerosis, 2009. 205(2): p. 579-83.

45. Chou, R., et al., Screening asymptomatic adults with resting or exercise electrocardiography: a review of the evidence for the U.S. Preventive Services Task Force. Ann Intern Med, 2011. 155(6): p. 375-85.

46. Adabag, A.S., et al., Relation of heart rate parameters during exercise test to sudden death and all-cause mortality in asymptomatic men. The American journal of cardiology, 2008. 101(10): p. 1437-43.

47. Okin, P.M. and P. Kligfield, Gender-specific criteria and performance of the exercise electrocardiogram. Circulation, 1995. 92(5): p. 1209-16.

48. World Health Organization. International Statistical Classification of Diseases and Related Health Problems 1oth Revision. 2016 25/10/2018];

Available

from:

http://apps.who.int/classifications/icd10/browse/2016/en.

49. Svensbergh, A., et al., ST-recovery loop of exercise-induced ST deviation in the identification of coronary artery disease: which parameters should we measure? Journal of electrocardiology, 2004. 37(4): p. 275-83.

50. Kronander, H., et al., Analysis of ST/HR hysteresis improves longterm prognostic value of exercise ECG test. International journal of cardiology, 2011. 148(1): p. 64-9.

51. Viik, J., et al., The effect of lead selection on traditional and heart rate-adjusted ST segment analysis in the detection of coronary artery disease during exercise testing. American heart journal, 1997. 134(3): p. 488-94.

52. Kronander, H., et al., Improved capacity of exercise electrocardiography in the detection of coronary artery disease by focusing on diagnostic variables during the early recovery phase. Journal of electrocardiology, 2005. 38(2): p. 130-8.

53. Thompson, W.R., N.F. Gordon, and L.S. Pescatello, ACSM's guidelines for exercise testing and prescription. 2009, Lippincott Williams \& Wilkins: Philadelphia.

54. Wallin, L. and L.H. Brudin, Physical working capacity determined by different types of bicycle exercise tests. Clinical physiology, 1988. 8(5): p. 529-37.

55. Pandolf, K.B., B. Givoni, and R.F. Goldman, Predicting energy expenditure with loads while standing or walking very slowly. $\mathrm{J}$ Appl Physiol, 1977. 43(4): p. 577-81.

56. Elia, M. and G. Livesey, Energy expenditure and fuel selection in biological systems: the theory and practice of calculations based on indirect calorimetry and tracer methods. World review of nutrition and dietetics, 1992. 70: p. 68-131. 
57. Rifkin, R.D. and W.B. Hood, Jr., Bayesian analysis of electrocardiographic exercise stress testing. N Engl J Med, 1977. 297(13): p. 681-6.

58. Brudin, L., L. Jorfeldt, and O. Pahlm, Comparison of two commonly used reference materials for exercise bicycle tests with a Swedish clinical database of patients with normal outcome. Clin Physiol Funct Imaging, 2014. 34(4): p. 297-307.

59. Wohlfart, B. and G.R. Farazdaghi, Reference values for the physical work capacity on a bicycle ergometer for men -- a comparison with a previous study on women. Clin Physiol Funct Imaging, 2003. 23(3): p. 166-70.

6o. Myers, J., et al., A Reference Equation for Normal Standards for VO2 Max: Analysis from the Fitness Registry and the Importance of Exercise National Database (FRIEND Registry). Prog Cardiovasc Dis, 2017. 60(1): p. 21-29.

61. Lindberg, A.S., et al., Field tests for evaluating the aerobic work capacity of firefighters. PloS one, 2013. 8(7): p. e68047.

62. Gavhed, D. and I. Holmer, Arbetslivsrapport 1998:29. Fysisk arbetsförmåga hos brandmän. Arbetslivsinstitutet, 1998.

63. Dorman, L.E. and G. Havenith, The effects of protective clothing on energy consumption during different activities. European journal of applied physiology, 2009. 105(3): p. 463-70.

64. Givoni, B. and R.F. Goldman, Predicting metabolic energy cost. Journal of applied physiology, 1971. 30(3): p. 429-33.

65. Taylor, N.A., et al., A fractionation of the physiological burden of the personal protective equipment worn by firefighters. European journal of applied physiology, 2012. 112(8): p. 2913-21.

66. Cavagna, G.A. and M. Kaneko, Mechanical work and efficiency in level walking and running. The Journal of physiology, 1977. 268(2): p. 467--81.

67. Smolander, J.L., S. Louhevaara, V. Koski, T., Uusimäki, H. Korhonen, O. , Advances in Industrial Ergonomics and Safety III, Proceedings of the Annual International Industrial Ergonomics and Safety Conference, Lake Tahoe, NV, June 1O-14 1991, ed. K.W. Ed and Y.J.W. Ed. 1991.

68. Inrikesministeriet, F., Inrikesministeriets publikationer 58/2007. Anvisning för räddningsdykning. 2007.

69. The Norwegian Labour Inspection Authority. Available from: https://www.arbeidstilsynet.no/tema/kjemikalier/royk-ogkjemikaliedykking/helseundersokelse-for-royk-ogkjemikaliedykkere/.

70. Stevenson, R.D.M., P. Wilsher, and K. Sykes, FireFit Steering Group. Fitness for Fire \& Rescue. Standards, Protocol and Policy, U.K. Chief Fire Officers Association, Editor. 2009.

71. National Fire Protection Agency, NFPA 1582 Standard on Comprehensive Occupational Medical Programe for Fire Departments. Vol. 2018 Edition. 2018. 
72. von Heimburg, E., et al., Performance on a work-simulating firefighter test versus approved laboratory tests for firefighters and applicants. Int J Occup Saf Ergon, 2013. 19(2): p. 227-43.

73. Todd Rogers, W., D. Docherty, and S. Petersen, Establishment of performance standards and a cut-score for the Canadian Forces firefighter physical fitness maintenance evaluation (FF PFME). Ergonomics, 2014. 57(11): p. 1750-9.

74. Punakallio, A., et al., Lifestyle factors predicting changes in aerobic capacity of aging firefighters at 3- and 13-year follow-ups. J Occup Environ Med, 2012. 54(9): p. 1133-41.

75. Kilbom, A., Physical work capacity of firemen. With special reference to demands during fire fighting. Scandinavian journal of work, environment \& health, 1980. 6(1): p. 48-57.

76. Saupe, K., M. Sothmann, and D. Jasenof, Aging and the fitness of fire fighters: the complex issues involved in abolishing mandatory retirement ages. Am J Public Health, 1991. 81(9): p. 1192-4.

77. Danielsson, U., H. Leray, and U. Bergh, Fysisk belastning och prestation. Effekter av ålder och erfarenhet vid aktiviteter inom räddningstjänsten. FOI Totalförsvarets forskningsinstitut. Vetenskaplig rapport., 2002.

78. Gibbons, R.J., et al., ACC/AHA/ACP-ASIM guidelines for the management of patients with chronic stable angina: executive summary and recommendations. A Report of the American College of Cardiology/American Heart Association Task Force on Practice Guidelines (Committee on Management of Patients with Chronic Stable Angina). Circulation, 1999. 99(21): p. 2829-48.

79. Diamond, G.A. and J.S. Forrester, Analysis of probability as an aid in the clinical diagnosis of coronary-artery disease. N Engl J Med, 1979. 300(24): p. 1350-8.

80. Genders, T.S., et al., A clinical prediction rule for the diagnosis of coronary artery disease: validation, updating, and extension. Eur Heart J, 2011. 32(11): p. 1316-30.

81. Piepoli, M.F., et al., 2016 European Guidelines on cardiovascular disease prevention in clinical practice: The Sixth Joint Task Force of the European Society of Cardiology and Other Societies on Cardiovascular Disease Prevention in Clinical Practice (constituted by representatives of 10 societies and by invited experts)Developed with the special contribution of the European Association for Cardiovascular Prevention \& Rehabilitation (EACPR). Eur Heart J, 2016. 37(29): p. 2315-2381.

82. Laukkanen, J.A., et al., Asymptomatic ST-segment depression during exercise testing and the risk of sudden cardiac death in middleaged men: a population-based follow-up study. Eur Heart J, 2009. 30(5): p. 558-65.

83. Hagnas, M.J., et al., Cardiorespiratory fitness and exercise-induced ST segment depression in assessing the risk of sudden cardiac death in men. Heart, 2017. 103(5): p. 383-389. 
84. Bodegard, J., et al., Symptom-limited exercise testing, ST depressions and long-term coronary heart disease mortality in apparently healthy middle-aged men. Eur J Cardiovasc Prev Rehabil, 2004. 11(4): p. 320-7.

85. Okin, P.M., et al., Prognostic value of heart rate adjustment of exercise-induced ST segment depression in the multiple risk factor intervention trial. Journal of the American College of Cardiology, 1996. 27(6): p. 1437-43.

86. Froelicher, V.F., et al., The electrocardiographic exercise test in a population with reduced workup bias: diagnostic performance, computerized interpretation, and multivariable prediction. Veterans Affairs Cooperative Study in Health Services \#016 (QUEXTA) Study Group. Quantitative Exercise Testing and Angiography. Annals of internal medicine, 1998. 128(12 Pt 1): p. 965-74.

87. Hodnesdal, C., et al., Rapidly upsloping ST-segment on exercise ECG: a marker of reduced coronary heart disease mortality risk. Eur J Prev Cardiol, 2013. 20(4): p. 541-8.

88. Lachterman, B., et al., Comparison of ST segment/heart rate index to standard ST criteria for analysis of exercise electrocardiogram. Circulation, 1990. 82(1): p. 44-50.

89. Viik, J., R. Lehtinen, and J. Malmivuo, Detection of coronary artery disease using maximum value of $S T / H R$ hysteresis over different number of leads. J Electrocardiol, 1999. 32 Suppl: p. 70-5.

90. Zimarino, M., et al., A comparison of the diagnostic performance of the $S T / H R$ hysteresis with cardiopulmonary stress testing parameters in detecting exercise-induced myocardial ischemia. Int J Cardiol, 2013. 168(2): p. 1274-9.

91. Kronander, H., et al., Diagnostic performance and partition values of exercise electrocardiographic variables in the detection of coronary artery disease--improved accuracy by using ST/HR hysteresis. Clin Physiol Funct Imaging, 2010. 30(2): p. 98-106.

92. Smith, D.L., et al., Pathoanatomic Findings Associated With DutyRelated Cardiac Death in US Firefighters: A Case-Control Study. J Am Heart Assoc, 2018. 7(18): p. eoo9446.

93. Ekberg, J. 2017, Myndigheten för Samhälsskydd och Beredskap (Swedish Civil Contingencies Agency).

94. Kodama, S., et al., Cardiorespiratory fitness as a quantitative predictor of all-cause mortality and cardiovascular events in healthy men and women: a meta-analysis. JAMA, 2009. 301(19): p. 2024-35.

95. La Gerche, A., et al., Cardiac imaging and stress testing asymptomatic athletes to identify those at risk of sudden cardiac death. JACC Cardiovasc Imaging, 2013. 6(9): p. 993-1007.

96. van de Sande, D.A., M.A. Breuer, and H.M. Kemps, Utility of Exercise Electrocardiography in Pre-participation Screening in 
Asymptomatic Athletes: A Systematic Review. Sports Med, 2016. 46(8): p. 1155-64.

97. Dores, H., et al., Subclinical coronary artery disease in veteran athletes: is a new preparticipation methodology required? $\mathrm{Br} \mathrm{J}$ Sports Med, 2018.

98. Ermolao, A., et al., Coronary CT angiography in asymptomatic middle-aged athletes with ST segment anomalies during maximal exercise test. Scand J Med Sci Sports, 2016. 26(1): p. 57-63.

99. Borjesson, M., et al., Cardiovascular evaluation of middle-aged/ senior individuals engaged in leisure-time sport activities: position stand from the sections of exercise physiology and sports cardiology of the European Association of Cardiovascular Prevention and Rehabilitation. Eur J Cardiovasc Prev Rehabil, 2011. 18(3): p. 446-58.

100. Gray, G., et al., The challenge of asymptomatic coronary artery disease in aircrew; detecting plaque before the accident. Heart, 2019. 105(Suppl 1): p. s17-s24.

101. Merghani, A., et al., Prevalence of Subclinical Coronary Artery Disease in Masters Endurance Athletes With a Low Atherosclerotic Risk Profile. Circulation, 2017. 136(2): p. 126-137.

102. Pepine, C.J., et al., Effects of treatment on outcome in mildly symptomatic patients with ischemia during daily life. The Atenolol Silent Ischemia Study (ASIST). Circulation, 1994. 90(2): p. 762-8.

103. Rogers, W.J., et al., Asymptomatic Cardiac Ischemia Pilot (ACIP) study: outcome at 1 year for patients with asymptomatic cardiac ischemia randomized to medical therapy or revascularization. The ACIP Investigators. J Am Coll Cardiol, 1995. 26(3): p. 594-605.

104. Sapin, P.M., et al., Exaggerated atrial repolarization waves as a predictor of false positive exercise tests in an unselected population. J Electrocardiol, 1995. 28(4): p. 313-21.

105. Youn, H.J., et al., Pattern of exercise-induced ST change is related to coronary flow reserve in patients with chest pain and normal coronary angiogram. Int J Cardiol, 2005. 101(2): p. 299-304.

106. Crea, F., P.G. Camici, and C.N. Bairey Merz, Coronary microvascular dysfunction: an update. Eur Heart J, 2014. 35(17): p. 1101-11.

107. Loffler, A.I. and J.M. Bourque, Coronary Microvascular Dysfunction, Microvascular Angina, and Management. Curr Cardiol Rep, 2016. 18(1): p. 1. 


\section{ACKNOWLEDGEMENTS}

When I first discovered the world of science during medical school, I was full of fascination and inspiration, but the path towards dissertation seemed complicated and almost eternal. Without all the support and assistance I have received throughout the years as PhD student, the completion of this dissertation would not have been possible.

Managing the clinical internship and residency with research has been challenging from time to time. In addition, the period for my doctoral studies has coincided with two new beloved family members as well as an extended mountain-life escape to Åre, far from the established networks of my research supervisors and babysitting relatives. Yet, I have experienced understanding, cooperation and creative solutions from supervisors, clinical directors, colleagues, family and friends, to be able to complete this research project.

I would like to thank the many people who contributed to this project in different ways. Some of you deserve special thanks.

First, I would like to express my deepest gratitude to my main supervisor Eva Nylander. Your supportive and encouraging attitude, profound physiological knowledge, clear communication, and your endless capacity to find time for constructive feedback have supported me and inspired me do to my very best. You are a true role model to me.

My co-supervisor Mikael Gustafsson, for raising the initial research questions of this project, for sharing knowledge and data, and last but not least for all the time and effort spent on coding and database queries.

My co-supervisor Meriam Åström Aneq, for your thoughtful advice and encouragement.

Firefighters and test leaders at the fire stations, for participation, cooperation and efforts to find and provide structured test result data.

Olof Malm, Malin Huss, and Anette Gylling, for valuable assistance in the review of medical records.

Emil Karlsson, for efficient initial data extraction from the study database.

Martin Nihlén, for personalised graphical artwork for the cover of this book. 
Mats Fredriksson, Karl Wahlin, and Lars Valter, for statistical advice.

My present and previous fellow doctoral students, especially Kristofer Hedman and Lena Forsberg, for sharing your scientific knowledge and practical experiences, a step ahead of me.

Kjell Jansson, Head of the Department of Clinical Physiology in Linköping, for promoting a research friendly climate at the clinic and for your flexible attitude during times of geographical distance.

All colleagues and staff at the Department of Clinical Physiology and at Åre Hälsocentral, for collaboration, sharing of knowledge, and a friendly, appreciated ambience.

Elin Wistrand, Malin Strand, and Lotta Gustafsson, for always helping out with various administrative issues.

Friends and family, for joyful moments to remember, giving balance to life.

Old and new neighbours, especially the BBV neighbourhood in Åre, for emotional and practical support throughout logistical challenges for our family.

My parents-in-law Cecilia and Elving and my sister-in-law Eleonor, for babysitting and valuable assistance.

My sister Olivia. Mum and Dad, for your endless belief in me and for always supporting me and my family in so many ways.

My dear Fredrik, for sharing a theoretical and practical interest in physiological adaptation to sports with me, but mostly for your support and for your love throughout good and bad.

Nils \& Ebbe, for filling my heart with love.

*

This research was financially supported by

- ALF Grants, Region Östergötland, Sweden

- Residents Physician Grants, Region Östergötland, Sweden

- Olav Axelssons memorial fund, Sweden 


\section{Papers}

The papers associated with this thesis have been removed for copyright reasons. For more details about these see:

http://urn.kb.se/resolve?urn=urn:nbn:se:liu:diva-159757 


\section{FACULTY OF MEDICINE AND HEALTH SCIENCES}

Linköping University Medicine Dissertation No. 1688, 2019

Department of Medical and Health Sciences

Division of Cardiovascular Medicine

Linköping University

SE-581 83 Linköping, Sweden

www.liu.se

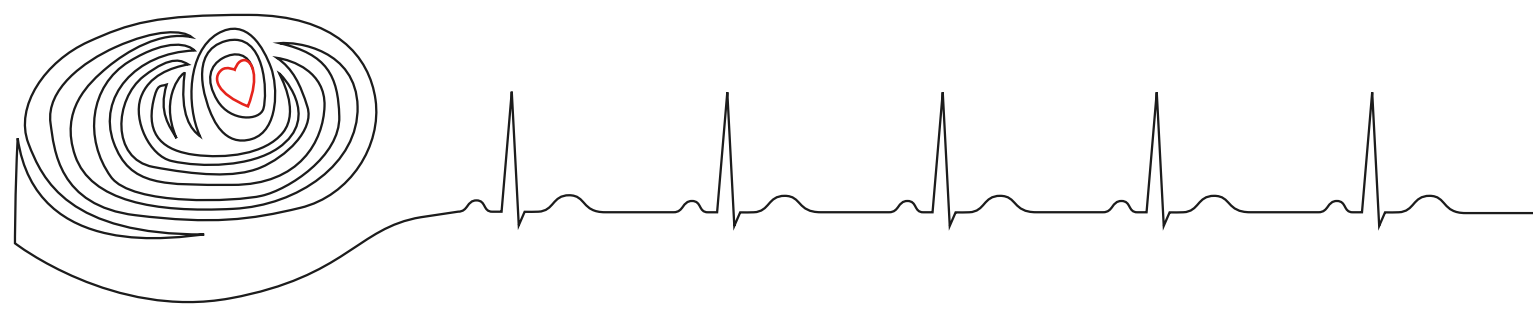

